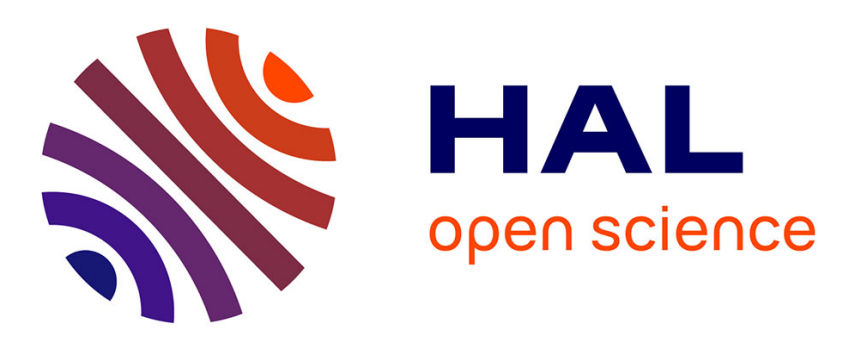

\title{
Developmental diversity in Mindreading and Metacognition
}

\author{
Sunae Kim, Ameneh Shahaeian, Joëlle Proust
}

\section{To cite this version:}

Sunae Kim, Ameneh Shahaeian, Joëlle Proust. Developmental diversity in Mindreading and Metacognition. J. Proust; M. Fortier. Metacognitive Diversity: Interdisciplinary approaches, Oxford University Press, 2018, 10.1093/oso/9780198789710.003.0006 . ijn_03036247

\section{HAL Id: ijn_03036247 \\ https://hal.science/ijn_03036247}

Submitted on 2 Dec 2020

HAL is a multi-disciplinary open access archive for the deposit and dissemination of scientific research documents, whether they are published or not. The documents may come from teaching and research institutions in France or abroad, or from public or private research centers.
L'archive ouverte pluridisciplinaire HAL, est destinée au dépôt et à la diffusion de documents scientifiques de niveau recherche, publiés ou non, émanant des établissements d'enseignement et de recherche français ou étrangers, des laboratoires publics ou privés. 
Developmental diversity in mindreading and metacognition

Sunae Kim, Ameneh Shahaeian \& Joëlle Proust

\section{ABSTRACT}

Although mindreading and metacognition are shared by all humans, they are variously influenced and shaped by cultural practices. A first aim of this chapter is to explain why children seem to present different patterns of development across culture for solving false belief tasks. Anthropological evidence will be offered suggesting that the tests devised for Western children might not be adequate outside Western cultures. Alternative practices and values, such as the willingness/refusal to express one's own mental states, the degree of autonomous agency allocated to young children, and the style of communication used in child-rearing might in part explain the timing differences in the development of mindreading. A second aim is to identify the sociocultural factors that might also differentially impact the development of metacognitive abilities. We propose that the cultural practices that regulate patterns of attention, ways of learning and communicational pragmatics should differentially influence the kinds of epistemic decisions that need to be monitored and the process of attribution of knowledge to the self in young children. On the basis of an experiment with German, Japanese and Yucatec Mayan children, we will present evidence for cross-cultural diversity in the development of implicit and explicit assessments of knowledge.

\section{Keywords}

Experience-based metacognition, analytic metacognition, mindreading, false belief task, informing, interactionism, autonomy, opacity, communication, holistic attention, observational learning, collectivism.

Mindreading ${ }^{1}$ is the set of abilities that allows us to predict and explain others' behaviour. For example, people infer what agents should think and do from their perspectives on a scene. Metacognition refers to self-evaluation and control of one's own epistemic states (perception, memory, reasoning). For example, you routinely assess what you can perceive, remember, or learn. Mindreading and metacognition, then, are both in the business of evaluating and

\footnotetext{
${ }^{1}$ We chose this word rather than "theory of mind" to accommodate the different conceptions and theories developed by the literature from child psychology, anthropology, and philosophy.
} 
controlling mental states and dispositions, and are shared by all human beings. They differ by targeting respectively others' mental states and one's own. As will be shown, they also seem to differ in the informational processes involved and in their developmental pattern.

Our aim in this chapter is two-fold. First, although mindreading and metacognition are shared by all humans, they can presumably be variously shaped and adjusted by cultural influences. This topic has received only sparse attention in the case of mindreading, and none in the case of metacognition. ${ }^{2}$ Our first aim, then, is to explore diversity in how children respectively develop their mindreading and metacognitive abilities. Our guideline will be, whenever possible, to associate anthropological and psycho-developmental evidence. Our second aim is to identify the types of cultural factors that explain the variations that are known, or suspected to exist, for each type of capacity. Whenever experimental evidence is lacking, we will offer conjectures. Our two-fold goal should allow us, as a side-aim, to clarify the relations between mindreading and metacognition, that is, to discuss the plausibility of a dual-process theory of metacognition, in which social values, practices and beliefs play their distinctive shaping roles.

The first section will present three popular theories of mindreading, along with evidence for developmental variations across culture; the factors involved in these variations will be discussed in light of anthropological evidence. The second section will explore the factors that might respectively shape metacognitive experiences and associated concepts. The third section will discuss these hypotheses in light of a developmental experiment testing three populations of children differing on the dimensions previously discussed.

\section{Mindreading across cultures}

What is mindreading?

Just as reading refers to the complex set of abilities for identifying thought contents on the basis of inscriptions, mindreading refers to the complex set of abilities for identifying others' mental states and dispositions to act on the basis of their verbal and gestural behaviour. Theory of Mind (ToM) refers to the view that mindreading consists primarily in representing conceptual relations between mental states such as beliefs and desires as a basis for behaviour prediction. In this framework, the experimental task that has been mainly used to test these abilities is the "false belief" task (FBT), in which a protagonist holds a belief that contradicts the reality; the child, as an observer, needs to recognise the protagonist's 'false belief', i.e. a

\footnotetext{
${ }^{2}$ See, however, Brennan, Vikan \& Dybdahl, (2007).
} 
belief that contradicts reality as known by the observer. Several tasks have been used to assess children's understanding of others' false beliefs. In most of these tasks, children are presented with a short narrative, like the following: Sally has put her marbles in the basket; in her absence, the marbles were moved to a box by Ann. Where will Sally look for her marbles when she returns? An intriguing common finding is that whereas three-year-olds systematically fail the FBT, responding that Sally will look in the location where the marble currently is, most five-year-olds respond correctly. ${ }^{3}$

In order to better understand how children come to acknowledge others' mental states, other types of situations in which such an understanding is involved have been explored. At what age do young children begin to distinguish reality from pictures, or an imaginary from a real object? For example, if told about someone who is eating food and about a hungry person who is thinking about food, can a child distinguish between the real food that can be touched or smelled and the imagined food? It was shown that children as young as three years know that an image of food is not "real" and cannot be touched or smelled (Harris, 1992; Harris, Brown, Marriott, Whittall, \& Harmer, 1991; Watson, Gelman, \& Wellman, 1998). But this understanding is only a first step in gaining an understanding of others' minds and being able to explain one's own and others' behaviour by referring to mental states.

Different kinds of accounts have been proposed to explain these findings.

1) The modular, nativist view hypothesizes that tracking others' belief is a core mechanism that starts developing in infancy (Kovacs, Teglas, \& Endress, 2010). Two informational mechanisms are hypothesized to jointly enable children's learning about mental states related to abstract concepts such as belief ("Sally believes that her marbles are in the basket") or desire ("Sally wants to play with her marbles"). First, a module allows children to automatically represent a given situation as seen from the viewpoint of another person. Second, a non-modular inhibitory selection process allows children to attribute appropriate representations of a situation to other agents. These two mechanisms are claimed to jointly enable children to remember different elements of the situation, to prohibit a prepotent response (such as the present location of the marble), by considering the question from the interpretee's viewpoint (Sally), rather than from the interpreter's own perspective (Ann, the observer, who knows that the marbles have been moved). The adequate level of inhibitory resources for solving the classical versions of FBT, however, only appears around the fifth year of development (Leslie, Friedman, \& German, 2004).

\footnotetext{
${ }^{3}$ As will be discussed later, this finding varies in different cultures.
} 
2) The "theory-theory" view, in contrast, hypothesizes that children build their mindreading abilities on the basis of both their observations of others' behaviour and of conversational inputs from adults and siblings, including mental state verbs (such as "thinking" and "wanting"). On this view of mindreading, explaining the behaviour of others requires hypothesizing that actions are determined by internal mental states such as desires, intentions, beliefs, and emotions. The folk psychological theory that children are supposed to build in order to interpret others' mental states is commonly referred to as a 'theory of mind'. For this reason, this approach is called a "theory-theory view of mindreading (Perner, 1991). ${ }^{4}$

3) A third family of accounts is the interactionist view, according to which mindreading emerges from intersubjective engagement, i.e., from acting jointly with others in recurrent social contexts (Carpendale \& Lewis, 2004). On this view, day-to-day interaction with other people provides routes to understanding others' mind in a way that a mere conceptual description of a situation, through conversation with adults for example, fails to offer. In order to discuss these alternative ways of understanding mindreading from the viewpoint of cross-cultural variation, let us first review the evidence that has been collected so far about mindreading diversity.

\section{Mindreading diversity: Psychological evidence}

Although research on theory of mind has predominantly been conducted in Western American and European cultures, some cross-cultural studies do exist. Earlier evidence suggested that mindreading was universal, developing everywhere at the same pace and with the same results. ${ }^{5} \mathrm{New}$ evidence paints a somewhat different picture. The relevant studies are reviewed below.

The case for developmental synchrony in the onset of mindreading through inter and intra cultural comparisons.

Significant cross-cultural research on false belief understanding began with Avis and Harris's

\footnotetext{
${ }^{4}$ Another mindreading theory, simulation theory, postulates that children learn to identify others' mental states by activating off-line their own decision-making processes. Because hybrid accounts associating Theory Theory and Simulation Theory are now often proposed (Goldman, 2006), and although radical simulationism largely overlaps with interactionism, we will not discuss Simulation Theory in this chapter.

${ }^{5}$ Avis and Harris (1991) found Baka children (hunter-gatherer group from Cameroon) have similar FB performances as children from Western cultures. Similar results were also found by Callaghan et al. (2005) for children from India, Canada, Peru, Samoa and Thailand; by Kuntoro, Saraswati, Peterson, and Slaughter (2013) for children from Indonesia (schooled middle-class or unschooled thrash-pickers) and from middle-class Australia, and by Barrett et al. (2013) for children from Ecuador, Fiji and China. The latter study used spontaneous-response tasks such as preferential looking, anticipatory looking or violation of expectation tasks, and found that 1 - to 4 -year-olds had a similar level in such implicit false-belief understanding.
} 
(1991) study with Baka children. Baka are pygmies living in the rain forests of South-East Cameroon; they are semi-nomadic and have a hunter-gatherer life-style. Baka children showed a similar pattern of development of false belief understanding to Western children: the majority of children failed at the age of three and rapid changes occurred between the ages of three to five years, after which children predominantly passed the FBT.

A 2001 meta-analysis of FBT performance in several thousand children showed that children of all studied cultures (from Europe, North and South America, East Asia, Australia and Africa) gradually come to understand false belief. A two-year age difference, however, was found across cultures between children -- a puzzling difference that will be discussed below (Wellman, Cross \& Watson, 2001).

Another study by Callaghan et al. (2005) provided what seemed to be stronger evidence for the universality of false belief acquisition. A total number of 267 children from five different cultures (Canada, India, Peru, Samoa and Thailand) were presented with a standardized FBT adjusted to each culture. They were all found to pass the task by 5 years of age, suggesting that the development of false belief understanding follows a universal pattern.

Consistent with these cross-cultural comparisons, studies of samples of children from different sub-cultural backgrounds within a single society presented similar patterns. One study showed that 3- to 7-year-old Indonesian children from distinct micro-cultures passed the FBT at the same age (Kuntoro, Sarawati, Peterson, \& Slaughter, 2013). Children in Jakarta were chosen from two distinct backgrounds - a group from middle-class families and a second group of unschooled children (with mostly uneducated parents) who worked as trash pickers. This research showed that their age of passing was the same as a group of Australian children, thus confirming the synchrony in the onset of false belief. A second study using three sub-samples of children in Iran showed that children from urban high and low socioeconomic status families and children from rural mountain villages all passed the FBT at a similar age (Shahaeian, Henry, Razmjoee, Teymoori, \& Wang, 2015). These groups of children were reported to be significantly diverse in terms of their parents' education and income, and their home environments. For instance, although the majority of urban high and low socioeconomic groups of children had a TV at home and had access to computers, most of the rural children did not have a TV at home, and very few had seen computers. Some of these children lived in tents along with other relatives while others had temporary or permanent homes in mountain areas. 
These findings seem to support the universality of false belief acquisition, with a few exceptional timing differences. However, the findings of other cross-cultural studies in this area draw a different picture.

The case for cross-cultural differences.

Other studies reveal intriguing timing differences in passing false belief tasks. A metaanalysis focussing on children from mainland China, Hong Kong, the United States, and Canada showed that the age at which false belief understanding develops may significantly vary across culture (Liu, Wellman, Tardif, \& Sabbagh, 2008). For example, children from Hong Kong understand false belief almost two years after children from China. This finding is surprising given the similarities between the languages spoken and the cultural and parental practices displayed in these two countries. The authors do not have an explanation for this timing difference. In addition to the results of this meta-analysis, two cultures, Samoa and Japan, further complicate this picture. Whereas Callaghan et al. (2005) had observed similarities in the timing of false belief acquisition for Samoan children compared to all other cultures in their study, Mayer and Träuble $(2013,2015)$ found a noticeably slower developmental timing in Samoa, with only $50 \%$ of 7 -year-old Samoan children passing the false belief task. At the same time, Naito and Koyama (2006) tested 211 Japanese children and found that a mastery of false belief understanding does not occur until the age of six to seven, i.e. two years later than children from Western and some non-Western countries. Finally, in contrast to these findings regarding Japanese children, a study by Ahn and Miller (2012) showed that 5-year-old Korean children outperformed their American counterparts in several tests of false belief understanding.

How might these differences be explained? Naito and Koyama (2006) speculated that Japanese children's comparative delay in acquiring false belief understanding results from the reduced reference to mental states that is characteristic of collectivist cultures, i.e., cultures emphasizing relatedness and harmony, rather than self-reliance and individualistic motives. ${ }^{6}$ On their view, Japanese people tend to refer more to behavioural states and to social constraints than to mental states (for example, saying that the boy will eat the apple because he is hungry, rather than because he likes apples). This account, however, fits uneasily with the data. Another study indeed found that Japanese children are not delayed in solving a FBT

\footnotetext{
${ }^{6}$ The individualism-collectivism dimension concerns the extent to which individuals consider themselves to depend on others for having personal attributes and a given life story. See Markus and Kitayama (1991). It will be further discussed in section 3 .
} 
when a non-verbal test is used (Moriguchi, Okumura, Kanakogi, \& Itakura, 2010). It was claimed that these findings conflict with the finding that in collectivist China, children pass the FBTs at the same age as children from individualist America (Liu, Wang, Luo, \& Su, 2014). The notion of "collectivist China", however, was independently found overly simplistic in the light of further findings demonstrating the relation between agricultural labour and individuation. ${ }^{7}$ Hence, the findings concerning China reported above might also fail to apply to China as a whole.

In summary: Children all solve FBTs irrespective of their culture at some point in their development. Timing differences have been found, but they seem to be modulated by incidental aspects of the tasks used. It is fair to say that the cross-cultural psychological research has not yet uncovered a consistent pattern of development of false belief understanding among children from different cultural backgrounds (for a similar conclusion, see Slaughter \& Perez-Zapata, 2014).

\section{Cultures and theory of mind: beyond false belief}

As noted earlier, most cross-cultural research on theory of mind development has tended to focus on false belief understanding. There is more to understanding others' minds, however, than merely understanding that others sometimes hold false beliefs. For example, children need to understand that perception is a source of knowledge. But although research has not reached any agreed upon conclusions about the trajectories of false belief development across cultures, we find more agreement among the studies investigating children's development of the understanding of the concept of knowledge. Remember that for children to be able to understand that one can hold a belief that is false, they first need to understand that there are specific ways of acquiring knowledge about events. Most of the studies following the leading-edge research of Wellman and Liu (2004) have shown that the sequence of theory of mind steps differs between Chinese and American children. Chinese children develop earlier than American children an understanding that people acquire knowledge from different sources, such as perception or testimony. Iranian children of three to five years of age, similar to Chinese children, were subsequently shown to outperform their Australian counterparts in passing knowledge tasks (Shahaeian, Peterson, Slaughter, \&

\footnotetext{
${ }^{7}$ Because paddy rice crops demand intense cooperation, they foster both a clanic social organisation and a collectivist psychology. Wheat cultivation, in contrast, fosters nuclear households and individualist psychology. (Talhelm, Zhang, Oishi, Shimin, Duan, Lan \& Kitayama, 2014).
} 
Wellman, 2011; Shahaeian, Nielsen, Peterson, Slaughter, \& Aboutalebi, 2014a). These results are indeed interesting. In Iranian culture, similar to some other cultures that dominantly express collectivist-interdependent values, elders' wisdom and knowledge are emphasized: giving respect to elders is a sign of respect for their wisdom and accumulated knowledge. Is the consistent finding that Iranian and Chinese children outperform their Australian and America counterparts in tests of knowledge access attribution related to different cultural values and practices? Why do Iranian children outperform Australian children in understanding sarcasm (Shahaeian, Nielsen, Peterson, \& Slaughter, 2014b). We attempt to explain these cross-cultural differences in the next section.

\section{Diversity in mindreading acquisition: action-based theories}

A principled difficulty in studying mindreading across culture has to do with the way in which mindreading is acquired. In a nutshell, in a "theory of mind" approach to mindreading, understanding others presupposes possessing the relevant concepts of mental states. Once mastered, these concepts are supposed to allow children to predict others' behaviour, understand false beliefs, and explain what others do as a function of the way they represent the world to be, i.e. by forming metarepresentations of their propositional attitudes (for example, by representing that Sally believes that the toy is in the drawer). This construct may be easily applicable in societies where children are read stories, conversed with, and treated as individual agents having their own specific desires, experiences, and life narratives (Hutto, 2008). It might be more difficult to apply in societies where children receive less linguistic input directed to them and acquire much of their social knowledge by observation and interaction with others, such as Madagascar, Papua New Guinea, Yucatec or Mopan Mayas.

Another angle on this topic is to observe with Stephen Butterfill (2013) that a merely theory-based view of mental state attribution fails to address the issue of the "evidential basis" (i.e. the informational source) of mindreading: Does observing scenarios of the Sally-Ann kind provide access to the same relevant information for reading others' minds as acting jointly with them? On Butterfill's view, the response is negative. When acting jointly with others, a child is more likely to identify others' goal than when merely observing others' actions. Goal ascription is a powerful way of learning from others' failures as well as their successes. For example, a child may learn where the peanuts are hidden by watching another agent try to open a box, even if the latter fails to open it. If the others' goal is the same as the agent's goal, goal ascription will be immediate and use first-order observation. Understanding 
others' goal through interactions with the self might thus form a first step in predicting others' behaviour, and pave the way for metarepresenting others' false beliefs. This important contrast between action and observation in acquiring a theory of mind will be further discussed below.

Butterfill's evidential condition is compatible with the notion that the information collected by children in joint action is used to build a theory of others' minds. Interactiontheorists (for short: interactionists), in contrast, reject the view that children literally attempt to read others' minds. This objection was first voiced by post-Piagetian theorists, who emphasized that children actively construct their understanding of the mind within cooperative social interactions (Carpendale \& Lewis, 2004). In a nutshell, interactionists hold that children elaborate their own representation of the mind in a gradual, action-oriented, and socially embedded way. Understanding the mind is a gradual process because it develops from implicit knowledge gained in interactional contexts to explicit verbalized notions (such as "believing"). It is action-oriented because action is the medium for learning. It is socially embedded because children's interacting with the world and communicating involve interlocutors. It is through acting that "the epistemic triangle", i.e. the relations between a young child, an object of knowledge, and an interlocutor, offers the adequate framework for explaining the development of social understanding (Carpendale \& Lewis, 2004). Some phenomenologist philosophers have later endorsed and radicalized this view: to understand others is to "actively participate in the generation of meaning" (Gallagher, 2012, p.193). Narratives present children with a rich repertoire of typical accounts of actions. Expectations about possible situations and accepted ways of addressing them are formed independently of any concept-based theory of mind (Gallagher \& Hutto, 2008).

A view related to interactionism proposes not that theorizing about the mind is irrelevant to mental understanding, but rather that, as any other type of attributive, communicative, or narrative activity, it involves a regulative practice that shapes minds, i.e. makes them receptive to the basic forms of inter-subjectivity relevant to a given cultural group (McGeer \& Pettit, 2002; Zawidzki, 2013). The capacity to attribute propositional attitudes such as desiring or believing to oneself and to others, then, is seen as parasitic on individual and collective regulation of agents' behavioural dispositions. The expression of "cognitive shaping" is meant to resist the view that mindreading, or any other cognitive ability, should be taken to be an independent "core" capacity subjected to various epigenetic influences. From a "mind-shaping" viewpoint, as we understand it, mindreading consists in a 
complex system of abilities for coping with social norms, organization of labour, along with their specific predictive constraints and verbal coordination needs.

To illustrate, let us come back to the case of sarcasm in Iran. As seen above, Iranian children outperform Australian children in understanding knowledge access and sarcasm, but are slower to understand belief diversity. A first explanation would be to say that Iranian conversation uses more indirect speech acts than Australian conversation. An interactionist account would, instead, relate sarcasm to deeply entrenched social practices and emotions, including how siblings interact among themselves and with their parents. For example, individuals should avoid expressing disagreement to their family members, and communicate what they think or desire without compromising basic conformity and harmony in the family. On this view, verbal and social behaviours are shaped by implicit social norms and practical know-how or habitus (Bourdieu, 1977) - including the delicate strategies for making others' aware of one's own preferences without imposing them to others. ${ }^{8}$ Conversely, interpreting others is made possible because everyone has been similarly shaped by specific sets of implicit social norms and rules. This account does not fully exclude the role of belief/desire attribution, but limits it to specific contexts, such as self-justification or normalization of deviant behaviour. Persuasion, however, would on this view again be framed by culturespecific prescriptions. On a mind-shaping view, then, the differences in timing in solving FB tasks do not reflect mere cultural influences in communicational styles on an independently developing capacity. They point to the diversity of the complex networks of cultural dispositions to act, learning practices, norms and theories embedding individuals' recognition of others' goals and intentions. ${ }^{9}$

Theory-theorists, however, may instead argue that cultural specificities illustrated, for example, by the numerous indirect speech acts in the Iranian conversation, do not shape, but merely facilitate children's capacity to acknowledge others' mental states by enhancing their motivation to do so. They might contend, for example, that, because the children are motivated to express preferences that are more acceptable by others, they need to learn how to reason about others' own preferences. Australian culture, in contrast, might facilitate children's understanding of the different ways of coming to know something (by sight, by hearsay, etc.). More generally, theory-theorists might recognize that cultures include different conceptions of how individual intentions cause actions (Zahrani \& Kaplowitz, 1993), frame

\footnotetext{
${ }^{8}$ See Bourdieu (1977, p. 73), and Jason Throop's analysis of the phenomenology of the will in different interactional contexts (Throop, 2010).

${ }^{9}$ For a distinction between cultural influence and cultural shaping, see the introduction (this volume).
} 
social situations in different terms (Nisbett \& Masuda, 2003), while maintaining that this diversity bears on optional features, not on the core features of mindreading (Lillard, 1998). One might finally notice that the details of the psychological and neural processes involved in interactionism have not yet been systematically studied, except for the role of mirror-neurons in children's observational learning ${ }^{10}$ (Gallese \& Goldman, 1998). The anthropology of mental shaping, fortunately, is in a position to offer interesting additional insights.

\section{The anthropology of mental shaping for mindreading}

Because anthropology studies behaviour-shaping practices, anthropologists tend to endorse some form or other of the interactionist conception of mindreading. From an anthropological viewpoint, it is a mistake to discuss how supposedly universal abstractly characterized cognitive functions, such as "interpreting others' mental states," are fulfilled in various groups. It is similarly misleading to try to describe in neutral terms the goals and values of a society, or the ways in which they categorize the entities in the physical and the social world. To make sense of the specific inferences of situated agents about their own minds and the minds of others, you need to look at the underlying practices through which their behaviours and minds are shaped. How do people cooperate with others? What are their collective decision making-processes? Who talks to whom and about what? These questions that should be addressed before devising experimental tests meant to measure people's social cognitive abilities.

There have been a few systematic psychological studies concerning the relations between social practices and specific cognitive shaping (Markus \& Kitayama, 1991, Nisbett, 2003) but much less have been devoted to the shaping of mindreading dispositions ${ }^{11}$ (Wassmann, Trauble, \& Funke, 2013). A few well-documented anthropological studies shed light on this issue. These studies have focused on "the doctrine of opacity" (Robbins \& Rumsey, 2008), according to which others' mental states are difficult or impossible to know, (an "epistemic claim" about what can be known about others) and/or should not be publicly discussed (a social rule). This "doctrine" is implicitly or explicitly endorsed by people of the Pacific area, extending from Philippino Ilongots, (Rosaldo, 1982), Papua New Guinean Ku Warus (Merlan \& Rumsey, 1991), Urapmins (Robbins, 2008), Bosavis (Schieffelin, 2008) and Korowai (Stasch, 2008) to Samoans (Duranti, 1993), Anutans from the Solomon Islands

\footnotetext{
${ }^{10}$ Mirror-neurons are neurons that fire both when acting and observing the same action performed by another agent.
} 
(Feinberg, 1998), Meso-American Mayans from Guatemala and Mexico, (Danziger, 2006, 2010; Gaskins, 1999) and Peruvian Junin Quechuas (Vinden, 1996). Endorsing an opacity doctrine does not mean at all that people are insensitive to others' having mental states (Keane, 2008, p. 480). It seems rather inspired by a social rule prohibiting the public attribution of intentions and other mental states to others. As we make clear below, this social rule is embedded in a network of beliefs and values.

Opacity cultures offer a striking illustration of the view that the normative practices related to the interpretation of others' mental states and the prediction of others' behaviour are shaped by various environmental, historical and societal features. Two normative dimensions seem to have had a major role, respectively regulating individual autonomy, and communicative economy. ${ }^{12}$

a) Autonomy shapes mindreading

The autonomy-heteronomy dimension concerns the value socially attributed to individuals' responsibility and privacy in thinking and acting. Its significance has been recognized both in developmental psychology (Piaget, 1948) and in anthropological studies. An emphasis on individual autonomy has a direct expression in the individuals' willingness to describe their own intentions and beliefs, and to accept intentional attributions. There are two ways of achieving autonomy, respectively privileging transparency or opacity as the best way of protecting one's own inner life (including selfish concerns and deceitful intentions) from others' intrusion.

In Western societies, people routinely use a mentalistic ${ }^{13}$ way of describing their own actions and plans. This transparency provides them with an individual source of justification of their actions. When individuals are construed as autonomous, coherent and responsible sources of their decisions, transparent access to their own intentions and beliefs is a basis for interpersonal cooperation, and is cultivated in various institutional practices (Christian confession, life narratives, legal system, etc.). The intentional interpretation of others' mental states, although relatively opaque, is made possible through verbally structured interactions designed to efficiently shape the associated behavioural patterns (promises, declarations of intent, etc.).

In societies that privilege the opacity doctrine, in contrast, restricting others' access to

\footnotetext{
12 Within the limits of this chapter, we can only, all too briefly, summarize how these norms have been hypothesized to shape behaviours. For a full discussion, see Kâğıtçıbaşı, (2005), Keller et al. (2004), Lillard (1998), Markus and Kitayama, (1991), Robbins \& Rumsey (2008), Throop (2011), and Wassman et al. (2013).

${ }^{13}$ A "mentalistic" description of one's actions consists in explaining one's reasons to act through specific beliefs and intentions.
} 
one's own thoughts and emotions is a major norm of interaction. ${ }^{14}$ Although the normative prevalence of mental privacy may be a social rule defining acceptable gossip, ${ }^{15}$ some groups justify it by the complexity of people's motives. Knowing others' mind is deemed "virtually impossible" by Bosavis, from Southern Highlands of Papua New Guinea, ${ }^{16}$ in contrast, mental state attribution in public is proscribed by the $\mathrm{Ku}$ Waru people from Western Highlands of Papua New Guinea, ${ }^{17}$ and tolerated for private explanatory and predictive ends by the Korowai (Southeastern West Papua) ${ }^{18}$. This continuum of attitudes toward opacity suggests that they reflect a trade-off between the "political" rule meant to maintain individuals' authority, i.e. ownership and autonomy on their inner life, and the need to predict others' behaviour $^{19}$. The political rule on individuals' authority that applies in a group, however, has specific shaping effects. For example, the habit of inhibiting the expression of one's own emotions in public may help control various aversive emotions. ${ }^{20}$ The absence of a need for public self-justification in terms of beliefs and desires may both restrict the scope of what individuals feel responsible for, and make implicit motivations more likely to guide actions (explicit expressions, being related to "transparent" practices, seem to impact individuals' autonomy and sense of well-being) (Hofer \& Chasiotis, 2003; Keane, 2008).

With these two divergent ways of dealing with autonomy, we now turn to divergent communication practices.

b) The economy of communication shapes mindreading.

The expression of "economy of communication" is meant to refer to the set of implicit social rules that regulate conversation and gestural expression in a given culture. According to Paul Grice (1989), communicating with another person presupposes attributing distinctive intentions and beliefs to the addressee and to oneself, which requires a full-blown mindreading capacity. A serious objection to Grice's claim is that monkeys and human infants unable to represent that their interlocutors have mental states are still able to understand and produce signals and utterances. ${ }^{21}$ It has been proposed that the syntax of attitudinal verbs,

\footnotetext{
${ }^{14}$ Robbins and Rumsey (2008), p. 416. Stasch (2008) p. 444, reports Korowai's saying "yepa yexulmelun", which means literally "Herself her thoughts," "Himself his thoughts". Stasch considers that opacity reflects an acute sensitivity to the risk of being mocked or manipulated by others. When priority is given, rather, to group interdependence and obedience, one can expect weaker forms of transparency and opacity to emerge. See Kâğıtçıbaşı (2005).

${ }^{15}$ Keane (2008).

${ }^{16}$ Schieffelin (2008),

${ }^{17}$ Rumsey (2008).

${ }^{18}$ Stasch (2008).

${ }^{19}$ Keane (2008).

${ }^{20}$ Groark (2013).

${ }^{21}$ See Proust (2016).
} 
such as "believe" or "desire", even if not required to communicate, might scaffold (through their sentential complements) children's representation of the corresponding mental states (De Villiers \& De Villiers, 2000). The total psychological evidence collected so far, however, fails to support the view that language syntax has a structural influence on mindreading (Unal \& Papafragou, this volume).

Anthropology, however, helps us complete this picture. Adult verbal communication implicitly teaches children what communication is for and how they are supposed to participate in it. Irrespective of communicated content, children implicitly absorb the structure of communication that prevails in their group, including their own personal status. Although this has not been studied in relation to mindreading, these environmental conditions cannot be ignored by mindreading theorists. In a number of societies, very young children are not spoken to. Three different types of communication structure have been described, which offer quite interesting contrasts (Ochs \& Schieffelin, 1982/2001). The Kalulis from Papua New Guinea do not treat nonverbal infants as dyadic partners of communication. The members of a household talk about children, but rarely, if ever, talk to them. Children only start being talked to by their mothers when they have mastered the words for [mother] and for [breast]. ${ }^{22}$ From then on, however, mothers model utterances for their children by taking the viewpoint of what the addressee expects to hear. Infants and toddlers are not publicly attributed desires or intentions.

In contrast, Anglo-American middle class caregivers communicate face-to-face with children, from infancy on. Dyadic proto-conversations are established long before language is acquired. Infants' vocalizations and toddlers' actions and utterances are considered as intentional social responses that need to be closely monitored (Ochs, 1982; Ochs \& Schieffelin, 1982/2001). When the meaning of utterances is judged unclear, caregivers propose rephrasing, and express their relative certainty in their proposed interpretation through prosody. Caregivers model sentences from the child's perspective, and are happy to use "baby-talk" to help children express their own desires and intentions.

Finally, in Samoa, a highly hierarchical society, social norms organize work and talk inside each group-level. Children are trained to assist higher-ranking individuals. For example, they are taught to repeat utterances, to report news to adults and to deliver messages. ${ }^{23}$ In case children produce unintelligible utterances, Samoan mothers, again, do not try to help their children clarify what they are trying to say.

\footnotetext{
${ }^{22}$ Ochs \& Schieffelin (1982), p. 25 sq.

${ }^{23}$ Ochs \& Schieffelin (1982), p. 40 sq.
} 
The diversity in norms and practices that anthropologists have documented not only, then, supports a mindshaping view, in which cognitive abilities are fundamentally structured so as to serve intertwined social goals. It also calls into question the validity of universal cognitive tests for evaluating core capacities. In particular, if mindreading is shaped by factors such as autonomy and communication, it is doubtful that false belief tasks offer a sensitive way of assessing how non-Western children understand and predict others' actions. Western children from middle-class backgrounds typically have had a prolonged communication partnership with adults. They are used to being asked questions by adults, and to ask questions of them. Pacific Islander children, and children from other traditional societies, are not so habituated.

There are additional irrelevant difficulties of the FBTs that non-Western rural children may experience. FBTs usually involve children's being asked questions. But experimenters may not notice that the asker is perceived by children participants as already knowing the correct answer: for school children, this is associated with a school exercise, which may discourage them to engage further in the problems presented to them. Using puppets or fictional characters to organize the contrast between true and false belief may be another obstacle for children from specific cultures where fictional narratives are discouraged (Danziger, 2010). These fictional verbal narratives might appear to the children of these societies as contrived and unnatural, and fail to elicit responses reflecting their sensitivity to others' mental states.

Let us take stock. Taken together, the documented variations in communicative goals across culture help us understand why anthropologists have emphasized that false belief tasks are a direct product of Western cultures. From infancy, Western children's social cognition has been channelled into specific routes. Western children have been scaffolded and encouraged, from infancy onward, to express their desires, beliefs and intentions, and thereby to recognize and use them to justify their actions to adults. Their early educational environment has habituated them to ask questions to which adults are eager to respond, and to respond themselves to questions to which adults already know the answer. They have been read narratives where intentions, desires, and plans, and others' mistaken beliefs and oversights play a central role. They are then prepared to solve false belief tasks in their last preschool year. ${ }^{24}$ Children from Pacific Islands or other similar societies, in contrast, are raised to become competent members of a community in which others' intentions are kept

\footnotetext{
${ }^{24}$ See Gauvain (1998), p. 40.
} 
private, and to only trust their own relatives and friends. ${ }^{25}$ These (or other) discrepancies in early communication practices might explain why children may appear to be delayed in understanding false belief, and why it may be easier for them to solve adequately framed implicit versions of the tasks.

When discussing mindreading diversity in this section, we found that the relevant prior question to ask was: "What is the information that children are using to predict others' behaviour"? The response that emerged as the most plausible was that, whether or not they all have innate dispositions to attribute beliefs and desires to others, children need to exploit the information (whether verbal or non verbal) that is practically made available to them in concrete, familiar interactions with others. A condition of reliability and fairness of mindreading tests, then, is that they should closely reflect the typical social situations to which children are confronted. Now a similar question needs to be raised about the information that children use to predict their own informational reliability when perceiving, remembering, learning or reasoning. As suggested in the introduction, metacognition has to do not with ascribing mental states to others, but with evaluating one's own cognitive states.

\section{Metacognition across cultures}

What is the information that children are using to assess their own cognition? Do children, irrespective of their own culture, reliably form feelings about what they remember, know, and so on? Two competing views about the development of metacognition offer different insights and propose different experimental methods for addressing these two related questions.

Two views about metacognition

On the first view, there is only one type of metacognition. It consists in reading one's mind and in finding out how it works (Carpendale \& Chandler, 1996; Flavell, 2000; Kuhn, 2000; Perner, 2012). On this view, children's metacognitive abilities depend on their conception of the mind, and hence, should reflect their mindreading competence. Evidence for this view is that a higher mindreading ability is longitudinally correlated with a higher metamemory (the ability to know what one can remember, how long to spend learning materials) (Lockl \& Schneider, 2007). Importantly, this longitudinal evidence consists in

\footnotetext{
${ }^{25}$ See section 3 below and Le Guen (this volume).
} 
verbal responses to tests proposed, over time, to cohorts of children. On this view, then, crossor intra-cultural (e.g., SES) developmental variations in metacognition might be traced back to variations in the development of mindreading.

On the second view, there are two forms of metacognition, developing sequentially and each having its own informational basis. The earlier metacognitive competence, also present in nonhumans, ${ }^{26}$ can be elicited by non-verbal tests in which children must evaluate what they can perceive or remember by strategically deciding whether to respond or not to respond to a question. ${ }^{27}$ Crucially, this early competence does not presuppose a mindreading competence. It is called "procedural metacognition" - or "experience-based" metacognition (Koriat \& Levy-Sadot, 1999), because it relies upon feelings of a certain kind, called "noetic feelings" (such as feelings of fluency, of uncertainty, of knowing) for guiding practical decisions, such as trying to remember, perceive, learn something, solve a problem etc. The later metacognitive competence, in contrast, depends on the mastery of concepts such as "truth", "knowledge", "memory", or "perception". ${ }^{28}$ It develops in Western children around school age, and is assumed to depend on inferences based on explicit beliefs and knowledge retrieved from memory rather than merely on feelings (Lecce, Demicheli, Zocchi, \& Palladino 2015; Lockl \& Schneider, 2007). For this reason, it is called "analytic" metacognition (Koriat \& Levy-Sadot, 1999).

Hence, the two views differ on whether analytic metacognition is the only form of metacognition there is (single-process view), or if there is in addition an experience-based type of metacognition that does not require concepts (dual-process view). This dual-process view of metacognition has been found to be more compatible than the single-process view of metacognition with the evidence available, including:

- the presence of metacognitive abilities in beings either with no mindreading (monkeys: see Couchman et al., 2012; Kornell et al, 2007), or before full-blown mindreading is present (infants: Gerken, Balcomb, \& Minton, 2011; Goupil,

\footnotetext{
${ }^{26}$ In primates: Couchman, Beran, Coutinho, Boomer, and Smith (2012), Kornell, Son, and Terrace (2007); in rodents : Kepecs \& Mainen, (2012).

${ }^{27}$ For an early study of the difference of children's metacognitive sensitivity in verbal and non-verbal tests, see Cunningham, \& Weaver, (1989).

${ }^{28}$ Koriat \& Levy-Sadot (1999) offered evidence for the dissociation between the two forms of metacognition in adult evaluations. Developmental evidence was provided by Balcomb and Gerken (2008) and Paulus, Proust, and Sodian (2013). Balcomb and Gerken (2008), for example, demonstrated that 3.5-year-old children were more likely to decline to answer to the memory trials in which they were less certain about their responses. The developmental gap between studies based on opt-out decisions and studies based on verbal reports constitutes a main argument in favour of the dual view of metacognition. A second argument consists in the comparative evidence of metacognition in primates, (Kornell, Son, \& Terrace, 2007), and in rodents (Kepecs \& Mainen, 2012).
} 
Romand-Monnier, \& Kouider, 2016).

- the dissociation in children's responses between using their feelings of uncertainty to decide what to do and verbally reporting what they know to others (Balcomb \& Gerken, 2008; Bernard, Proust, \& Clement, 2015; Paulus et al., 2013).

- the coexistence, dissociation and occasional interaction of adults' feeling-based and analytic predictive evaluations (Koriat \& Ackerman, 2010; Schwarz, this volume).

On the dual-process view, cross- or intra-cultural (SES) developmental variations in metacognition might be traced back to variations both in children's metacognitive experiences and in their mindreading sequence and developmental pattern.

Additional evidence for such dissociations in children will be presented in section 3 below. We will assume in the remainder of this article a dual-process viewpoint about metacognition. $^{29}$

\section{Metacognitive cross-cultural diversity: potential sources}

Granting that there are two forms of metacognition, are they both susceptible to be influenced by cultural practices? Before discussing this issue, let us observe that many metacognitive capacities and experiences are common to all people around the world.

1. Infants of all cultures, from about 10 months, actively seek relevant information in a behaviour called "social referencing". ${ }^{30}$ When confronted with a new, potentially dangerous situation, they look at their caregivers. If the adult looks relaxed, they are eager to explore it. If the adult appears fearful, they rather avoid it (Feinman, 1982). This behaviour involves sensitivity to new information, and to this extent, is an early form of procedural metacognition.

2. Declarative pointing, expressing the sensitivity of 10 month to 1 -year-old infants to new, relevant information has been shown to be present in all seven cultures tested (Liszkowski, Brown, Callaghan, Takada, \& de Vos, 2012). Because

\footnotetext{
${ }^{29}$ For a full defence, see Proust $(2012,2013)$.

${ }^{30}$ Susan Gaskins (1990) noticed that Mayan infants do little social referencing, possibly because they are used being constantly monitored.
} 
declarative pointing requires sensitivity to new and relevant information, it involves procedural metacognition (Proust, 2016).

3. Evidence for meta-communicational monitoring, as reported in ethnography, suggests that every human culture assesses fluency, relevance, and informativeness in one's own and in others' speech and behaviour. ${ }^{31}$

4. The experience described in English as a 'tip-of-the-tongue' experience has been documented in speakers of forty-five languages (Schwartz, 1999). A tip of the tongue experience allows speakers to predict their ability to utter a given word, and hence, belongs to procedural metacognition.

What needs to be investigated, however, is whether variability in practices, values and beliefs might modulate children's sensitivity to uncertainty in specific tasks and contexts, that is, their metacognition.

\section{Beliefs about capacities vary, and generate different kinds of metacognitive experiences}

Because analytic metacognition requires children to understand concepts such as perceiving and believing, its development is closely correlated with mindreading, as has been shown in the case of German children (Schneider, 2008). The variations that we found above in the developmental pattern of mindreading based on the dimensions of transparency/opacity and of communication economy should, then, also impact analytic metacognition. Variations in analytic metacognition, in turn, have been shown to modulate metacognitive experiences. Distinctive self-theories (theories about who one is) influence older children's and adolescents' judgments of competence in given academic fields (Yan \& Oyserman, this volume). For example, gender stereotypes might divert female students from studying mathematics, and generate in them a general lack of confidence when tested in maths (Spencer, Steele and Quinn, 1999). Indeed, middle-school girls have been shown to perform less well than boys, and to experience a task as more difficult than boys experienced it, when it was presented as geometry. When it was presented as a memory game, however, girls outperformed boys and found the task less difficult than boys (Hughet \& Régner, 2007).

Granting the extreme diversity in humans' beliefs concerning the nature and origins of competence of individuals (Lillard, 1998) and the scarcity of studies about variations in metacognition, top-down effects similar to gender- and ethnic biases across culture remain to be investigated. Independently from local beliefs and theories, however, cognitive practices

\footnotetext{
${ }^{31}$ See for example, Ku Waru's metalinguistic expressions reviewed in Merlan and Rumsey (1991), p. 347 sq.
} 
might also play an implicit role in shaping metacognitive experiences in infants and young children.

\section{Cognitive practices vary, and generate different kinds of metacognitive experiences}

Anthropological and psychological studies point to three main sources of variability in cognitive practices, i.e., familiar, culture-specific ways in which information is selected and organized. They respectively relate to how children attend to the world and form memories, how they learn to learn, and how they learn to communicate. We will propose that these three sources of cognitive variability might directly affect children's metacognitive practices, i.e. how they evaluate their success in perceiving, remembering, communicating or reasoning. Due to lack of sufficient experimental evidence, most of the proposals to be discussed are at this point heuristic tools for further research.

a) Attentional focus and metacognition

Cognitive psychologists have emphasized that attentional focus is rooted in attentional practices transmitted by caregivers to children. While in the West, (middle-class) mothers tend to attract their children's attention to salient objects in a situation, focusing on their specific properties, Asian (and working class Western) mothers tend rather to emphasize contextual aspects of a situation (Nisbett \& Miyamoto, 2005). For example, they describe background features of the scene, which leads children to perceive the object and the field as a whole, and to bind them in their memory. Middle-class American mothers label toys, describe their properties, and hence, implicitly motivate their children to learn proper names earlier than verbs. By the same token, they implicitly teach the children how to encode a situation analytically. Asian mothers, in contrast, engage their children in social routines and make verbs more salient to them than proper names. Verbs, however, express a relation between an agent, a target, and a type of action. They implicitly teach their children to attend to the relational, holistic aspects of a situation (Nisbett, Peng, Choi, \& Norenzayan, 2001; Nisbett, 2003).

Diversity in cognitive habits immediately maps onto metacognitive habits. Children select their attention focus and adjust the amount of effort to be devoted to a given task as a function of the specific attention patterns transmitted to them. Making certain perceptual or memorial elements salient should in turn determine how children implicitly assess their perception or their memory (and then, shape their procedural epistemic sensitivity). Confronted with the same input, Western children should tend to assess the precision of 
object-centred perceptions and memories. Eastern children, in contrast, should tend to assess the precision of their contextual encoding of a global event. Although the relations between object-centred and holistic attention, on the one hand, and metacognitive feelings such as feelings of knowing, of familiarity, of being right, on the other hand, have not been directly investigated, a little more is known about learning and its associated metacognition.

b) Observational learning (autonomous cognitive agency), instructional learning (heteronomous cognitive agency) and metacognition

Object-focused attention has a privileged role in Western types of formal learning (i.e. in instructional learning): an instructor teaches the properties of objects in a way detached from the present situation, but in accordance with a general educational program. ${ }^{32}$ In this type of education, children have to evaluate whether they understood the material presented and learned what the instructor intended them to learn. Children's metacognitive evaluations within a Western instructional context have been widely investigated. It appears that Western first graders are already sensitive to the relative difficulty of a memorizing task but do not select learning strategies based on difficulty, as third-graders can do (Koriat, Ackerman, Lock1, \& Schneider, 2009). In addition, third graders, when allowed to spend as much time as needed to learn given items, are able to predict their future recall. They do so by using a subpersonal (unconscious) heuristic predicting 'that the more time they spend studying an item, the less likely they are to recall it in the future.' ${ }^{33}$ Would this specific heuristic be acquired in the absence of any instructional learning? One might speculate that its acquisition closely depends on the highly structured and recurrent daily exercises that Western children perform as part of their curriculum. Children with no formal instruction, however, might develop alternative heuristics for knowing when they know.

Many children around the world (Polynesia, Melanesia, Africa, India), whether they receive formal instruction at school or not, mainly learn by observing older children and adults' behaviour and overhearing what is said (Gaskins \& Paradise, 2010, Rogoff, MejíaArauz, \& Correa-Chávez, 2015). Observational learning differs from instructional learning in at least three ways: 1) in the social context in which learning occurs: within the family group,

\footnotetext{
32 Pedagogies (such as the Montessori method) relying on peer teaching and modelling do not belong to formal learning as defined here.

${ }^{33}$ Koriat et al. (2009), p. 275. As in most forms of procedural metacognition, time and effort heuristics become consciously available through noetic feelings.
} 
rather than in a dedicated place, 2) in the type of skills to be learned: familiar and highly meaningful know-how rather than abstract contents and 3) in the active versus passive engagement of children (Gaskins \& Paradise, 2010).

Here again, metacognitive diversity should automatically result from learning diversity. When children are free to decide what to learn, when to learn, and how long to learn, they also need to apply implicit heuristics to determine when to stop observing their model. Although no study has yet been devoted to this issue, one might expect that judgments of observational learning, based on effort heuristics comparable to those used in formal learning tasks, are used by older children to determine how long they need to watch in order to learn.

An example of the cultural impact of learning modes is offered by a fascinating crosscultural study of imitative learning. Eighteen-month-old European infants have been shown to be more likely to imitate the specific way of using a new toy if the experimenter first looks at them and talks to them while performing the action than when they had merely observed him/her perform the same action (Csibra \& Gergely, 2011). Hence it has been claimed that child-directed interactions through adults' ostensive behaviour is a condition for early learning. A popular theory is that the ostensive signals directed at infants indicate to them that upcoming information is relevant and generalizable (Csibra \& Gergely, 2009). Ostensive signals - e.g., eye contact, infant-directed greeting -- are supposed to attract infants' attention to an upcoming information target (Csibra \& Gergely, 2009). Ostension has been further hypothesized to automatically control infants' learning, i.e. independently from culture.

However, in contrast to US and European infants, Mayan infants are rarely if ever exposed within traditional settings to pedagogical teaching. To test whether ostensive signals also facilitate learning in infants with no exposure to instructional interaction, Shneidman, Gaskins, and Woodward (2016) examined whether Yucatec Mayan infants imitate more after having observed an agent interact with a toy new to them only when first presented with an ostensive cue. What they found was that, whereas Mayan infants imitated more during their second visit to the test-room, their imitation rate was in no way influenced by ostensive signalling. US children only imitated more in their second visit only if they had been directly addressed in the first session. They seemed to have reasoned - when first directly addressed that a particular experimenter had information relevant to them. The resulting belief was retained in the second session, when the children were no longer addressed. Mayan children, in contrast, did not form such a hypothesis. This remarkable study shows that infants' sensitivity to relevance does not depend on an innate signalling device, but is rather based on whether their observational abilities have been shaped autonomously (learning being driven 
by the child's own appreciation of task's demands) or heteronomously (by relying on caregivers' cues). In the autonomy case, metacognition is exercised on the basis of the child's own assessment of the information to be collected. In the heteronomy case, adults' signals work as an external metacognitive device that directs children's attention.

This example also suggests that autonomous learning is related to holistic attention. Ostensive signals make a specific object or a specific property salient to children, and hence, encourage what Nisbett (2003) has called "analytic" (object-centred) attention. Paucity in ostensive signalling might promote in children a more inclusive or distributed exploration of situations and events. Interestingly, the same association between heteronomy and objectcentred attention is found in the Western patterns of parental involvement in children's play. Western parents enter into play with their children as peers, while also scaffolding children's attention to the game. In contrast, Indian mothers "don't see it as their business to direct play" and play rarely with their children (Rogoff et al., 1993, p. 107). The attentional pattern of Indian children, however, remains to be investigated.

In summary, Western parents exercise metacognition on behalf of children (selecting what is important to learn, and what can be learned). They train a given form of attention and its associated metacognitive monitoring. Caregivers from non-industrial cultures favour instead children's independent metacognition, by allowing them to freely explore opportunities and select their own informational goals as a function of their self-paced control of what they need to learn. Learning style, then, might modulate children's access to different types of information, and make specific procedures of metacognitive monitoring and control more readily available to them. In particular, the Westerners' biases and illusions about learning generated by their wrong folk theories might be absent in observational learners. This remains to be tested.

c) Communication pragmatics and metacognitive diversity in children.

In section 1, we studied the influence on mindreading of implicit social rules that regulate conversation and gestural expression in a given culture (such as talking to infants face-to-face or not). Now we explore how variations in the pragmatics of communication - i.e., in the contextual expectations, beliefs and inferences on which the transmission of meaning depends - might influence metacognitive diversity. Anthropologists have often emphasized that communication in Pacific Island and Mayan societies (Danziger, 2010; Rosaldo, 1982) as well as in other traditional societies (Ochs-Keenan, 1976) fails to be regulated by Paul Grice's four "maxims of conversation" (Grice, 1989). These maxims are cooperative principles that 
speakers and listeners need to observe or assume in order to make sense of each other's utterances. They respectively concern utterance quality (aim at truth!), quantity (be as informative as required!), relation (be relevant!) and manner (be brief and clear!). For Grice, flouting these maxims is possible, but violations are meant to trigger specific inferences in listeners.

Anthropologists have argued that Grice's maxims need to be reconsidered in light of the various needs of coordination across culture. For example, Malagasy speakers value information as a precious asset, and reserve true and informative utterances for their relatives and friends (Ochs-Keenan, 1976). Mopan Mayas use a similar restrictive maxim of quantity ("say as little as possible") (Danziger, 2010). To make themselves less predictable, they deliver as little information as possible about their whereabouts and intentions, and take lying to be a rational response to unfamiliar addressees. Hence, children are implicitly encouraged to closely monitor and control the amount of information as a function of context. Just as they learn to keep their utterances as vague as possible in responding to factual questions, they progressively learn to use indirect ways for obtaining information about what others think or do (see Le Guen, this volume, about Yucatec Mayan commucation).

This variation in guiding one's communication through specific implicit rules should impact both procedural and analytic metacognition. Analytic metacognition develops when agents become reflective about their practices, a relatively late achievement. Children, however, do not need to have a conceptual representation of how to communicate for practically assessing the implicit cues relevant to what they should tell and to whom. Deciding, in a given context, whether to volunteer or retain elements of information, when asked a question, and how to frame a question to obtain the relevant information, when asking a question, are typically a matter of procedural metacognition (or, more exactly, procedural meta-communication: Proust, 2016). Variations in procedural meta-communication are illustrated by the various ways in which toddlers select specific informational goals (what they want to know), express them to caregivers or peers, and how long they persist asking if no response is immediately coming. Nonverbal cues such as gaze direction, gestures, subtle facial and postural changes, are favoured in many traditional cultures for asking or responding (such as the Mayan and Indian families studied in Rogoff et al., 1993). Mayan toddlers are more likely to seek clarification of ambiguous situations through gaze, whereas middle-class US and Turkish children are more likely to use speech, as do their respective caregivers (Rogoff et al., 1993, p. 73). Gauvain, Munroe, \& Beebe, (2013) showed that the number of information-seeking questions among 3- to 5- year-old children across four non-Western 
Cultures, (Garifuna in Belize, Logoli in Kenya, Newars in Nepal, and Samoans,) did not differ from that of Western children, in a study by Chouinard, Harris, \& Maratsos, 2007. NonWestern children in the sampled populations, however, produced much less "why" questions than Western children, possibly as a consequence of an implicit social rule rejecting explanatory questions as insolent. ${ }^{34}$ This difference does not indicate that children are any less interested in explaining phenomena. It reminds us again that accessing children's own perspective on what they want to know requires the experimenters' adjusting testing methods to local practices.

\section{Opting-out from informing versus explicitly attributing knowledge to self: an experimental study across three cultures.}

We saw, in section 1, that mindreading performances present variations across culture. We proposed that such variations were compatible with a view in which mindreading is a complex set of dispositions that is dynamically shaped by social norms, beliefs, expectations and practices. As an application of mindreading to understanding one's own mind and mental functioning, concept-based metacognition also appears to be subject to cultural influences, originating in various representations of mental operations. We observed in section 2 that it is likely that different concepts about the self, or about competences, directly influence children's metacognitive experiences. We explored, in addition, how variation in attention patterns, in learning mode and in the pragmatics of daily communication, might also affect variations in children's metacognitive sensitivity. In this section, we will confront our former hypotheses with empirical evidence about procedural and analytic metacognition related to information and knowledge in children from large cities in Germany (Münich), Japan (Kyoto), and Yucatec Mayan villages. ${ }^{35}$ The following table summarizes some of the main dimensions of socio-cognitive values that might impact metacognition in the groups of children under study.

\begin{tabular}{|l|c|c|c|}
\hline & Industrial & Individualism & Autonomy \\
\hline Germany & + & + & - \\
\hline Japan & + & - & - \\
\hline
\end{tabular}

\footnotetext{
${ }^{34}$ Middle class children may often use "Why" questions for non-epistemic reasons, such as dominating a conversation.

${ }^{35}$ Kim, Proust, Petatillo, Le Guen (in preparation).
} 
Yucatec Maya

Fig.1. Socio-economic values across the cultures investigated.

The contrast between traditional, pre-industrial societies, and industrial societies, although not explicitly discussed until now, needs to be mentioned when comparing developmental patterns of children from big cities with children from small rural village (Henrich, 2014, Sahlins, 1983, Schooler, 2007). In pre-industrial, traditional cultures, economies tend to be primarily agricultural and subsistence-oriented. Because of a limited division of labour within families and clans, populations live in villages, where hierarchical solidarity underlies social unity. In industrial societies, technology enables mass production, based on an extreme division of labour, and generates high population concentrations in large cities. Industrial societies promote a modular form of social organisation, i.e. an organization based on atomistic and opportunist associations (Shore, 1996). This basic socio-historical dimension is important to understanding how types of attention, communication and learning play the role they do in each kind of cultural group (Greenfield, Maynard \& Childs, 2003, Henrich, Heine \& Norenzayan, 2010).

The individualism-collectivism dimension concerns the extent to which individuals consider themselves to depend on others for having personal attributes and a given life story. In collectivist cultures, the emphasis is on relatedness of individuals to each other and on harmonious interdependence. In individualist cultures, relatedness to others is less recognized or valued. Individuals, rather, perceive themselves as different from others and self-contained. Valuing self-realization leads individuals to attend to their own situation and motives, to assert their own special attributes and to strategically organise their recognition by others (Markus \& Kitayama, 1991). ${ }^{36}$

The autonomy-heteronomy dimension concerns the extent to which individuals' responsibility in thinking and acting is encouraged in a culture (Kâğıtçıbaşı, 2005). Although this dimension has significance in a number of domains of human agency, it is specifically reflected in different cultural beliefs and practices associated with childrearing and teaching. As discussed above, caregivers from heteronomy-oriented cultures think it is their role to control what their children should learn within a specific developmental timeline. In contrast, caregivers from autonomy-oriented cultures allow children to freely choose their own learning tasks and goals with little or limited adult input and direct guidance. Mayan children

\footnotetext{
${ }^{36}$ For an alternative conception of this dimension, see Keller (2012).
} 
however, are supposed to play their role in the family economy, and when given specific orders, they are not allowed to disobey their parents (Gaskins, 1999).

Granting the aim of clarifying the existence of diversity in metacognition, we need to contrast the performance of three groups with distinctive "dimensional profiles", in the two forms of metacognition that have been distinguished in the literature: procedural and experience-based vs. explanatory and conceptual. Experimental paradigms have been specifically devised for eliciting each type of metacognition. Opt-out paradigms are used to test procedural metacognition in young children, because they allow subjects to express their confidence level implicitly, by selecting a course of action (choose or decline a task; e.g., Balcomb \& Gerken, 2008). Questioning children verbally about what they know is the standard way for testing their conceptual metacognition (e.g., Rohwer, Kloo, \& Perner, 2012). The experimental paradigm to be described below conjoins in a fixed order the two types of experimental tests: the same children are first proposed an opt-out task (do you want to inform this person about what this box contains?), followed by a knowledge self-attribution task, also called 'explicit task' (do you know what this box contains?) (Kim, Paulus, Sodian, \& Proust, 2016).

One might argue that, when asked whether they want to inform another person, children need to use their conceptual understanding of knowledge or ignorance in order to determine whether or not they want to inform another person. This interpretation can be resisted, however. Monkeys are able to request information when performing a cognitive task and can indicate what they can remember or perceive with no mindreading ability (Couchman et al., 2012). Infants can decide to perform or not to perform a cognitive task (such as asking a question) on the basis of the feelings of uncertainty that are elicited by the task (Goupil et al., 2016). Similarly young children can also accept to respond to the question embodied in our informing task by following an accessibility or fluency heuristic (whenever a response is immediately available, I can respond/inform). Whereas strategic communication (e.g. selfjustification, lying) and verbal reports about one's own knowledge engage mindreading abilities, merely asking or responding to a question, or accepting to inform, engage procedural, experience-based metacognition. (This of course would no longer hold when information is perceived as sensitive by the potential informer, and hence, becomes a strategic issue).

A finding to the effect that children's accuracy in reporting what they know is higher than or identical with their accuracy in appropriately informing another person, would be 
hardly compatible with a dual-process view of metacognition. We expected instead that, in agreement with a dual-process view, the opt-out, informing task would implicitly elicit in children a higher sensitivity to their own knowledge states than the explicit verbal report task. Asking a child whether she knows or does not know, without immediate relation to a cooperative goal, refers to a classroom situation, or to a context engaging a self-concept. When primed with a knowledge question, then, children should tend to be more sensitive to the aversive dimension associated with ignorance than to the joint interest of reliably assessing what they know (elicited in a cooperative task). As a result, we expected children to be more reliable in adjusting their informing decision to what they know, than they are in adjusting their verbal knowledge report to what they know.

In order to test children's performance in the two tasks, we needed to manipulate what children knew about a given fact. By 3 years of age children understand that perception leads to knowledge (e.g., Pratt \& Bryant, 1990). In the task proposed, following Rohwer et al.'s (2012) paradigm, what children could know about the location of a toy differed across three conditions. In the Full knowledge condition, children were presented with a toy and an empty shoebox and were told that the toy would be hidden in the box, and watched it being hidden. In the Ignorance condition, children did not see any object, but were merely told that a toy would be hidden in the box. In the Partial knowledge condition, children were first presented with two different toys and were told that only one of them would be placed in the box.

To summarize: In the full knowledge condition, children saw the hiding of the object whereas in the partial knowledge or in the Ignorance condition, they did not see it. In the informing task, the same children were asked whether they would agree to inform another person whose view of the box was blocked during the entire experimental session. If they agreed to inform, they were asked to inform the other person. If they did not, the experimenter informed the other person. In the explicit task, no ignorant person was sitting next to the child. In both tasks, children received the same three conditions as described above in a counterbalanced order. ${ }^{37}$

Our initial findings with German children supported the predictions (Kim et al., 2016). The type of test influenced metacognitive accuracy. In the explicit task, 32 3- to 4-year-old German children were significantly less accurate in the Partial knowledge condition compared to the other two conditions (see also Rohwer et al., 2012). In the informing task, (partial

\footnotetext{
${ }^{37}$ Children's accurate responses were coded as follows: In the explicit task, children report that they do know in the Full knowledge condition; they report they do not know in the Partial knowledge or Ignorance condition. In the informing task, children decide to inform and inform correctly about object identity in the Full knowledge condition; decline to inform in the other two conditions. For more coding details, see Kim et al. (2016).
} 
knowledge condition), children displayed a higher sensitivity to their own incomplete knowledge (i.e., by reporting that they did not want to inform) than in the explicit task.

Based on these findings, we then asked whether this contrast, which we interpret as evidence for a dual form of metacognition, is modulated by culture. We tested a new group of German children and Japanese children (Kim et al., under review), and a group of Yucatec Mayan children (Kim et al., in preparation). Our German participants belong to an industrial, individualist and non-autonomous culture. Our Japanese participants belong to an industrial, collectivist and non-autonomous culture. Our Mayan participants, in contrast, belong to a non-industrial, collectivist and autonomous culture (see Figure 1 above). They live in small isolated rural Mayan-speaking communities, where childrearing is collective rather than dyadic and learning mainly observational. Mayan children are considered to be independent beings and are expected to learn by observing their family's ongoing work. They are autonomous in selecting when to attend, what to attend, and how long (Gaskins \& Paradise, 2010). Mayan children, then, live in a culture that differs from the other two groups by being non-industrial and by promoting autonomy.

In all three groups, we gave children the same informing and explicit task as described above. We replicated our own findings with a new group of 4-year-old German children. Interestingly, 4-year-old Japanese children displayed a similar pattern of responses as German children. In other words, the dissociation between experience-based (measured via the informing task) and analytic metacognition (measured via the explicit task) was observed in Japanese as well as in German children (See Figure 2). Would these two types of findings be also present in Yucatec Mayan children?

No dissociation of performance was found between the two tasks (informing/reporting knowledge) among Yucatec Mayan children. In both tasks, children's performance was significantly lower in the partial knowledge condition than in the other two conditions. Mayan children, in addition, revealed a distinctive overall overconfidence bias. For example, in the ignorance condition of the explicit task, when shown no object, they reported in more than half of the trials (55\%) that they knew where the toy was located, whereas the German 4-yearolds did so in about $20 \%$ of the cases (Kim et al., 2016), and the Japanese participants in $8 \%$, (Kim et al, under review). Note again that the findings in the literature show that Western children as young as 3 year-old performed well in this condition (Pratt \& Bryant, 1990). 
In order to further highlight differential performance across the three groups, children's performance in the informing task is presented in Figure 3 through their decision to inform (as opposed to their refusal to inform). ${ }^{38}$

Figure 3 about here

These cross-cultural findings raise new questions. In contrast to German and Japanese children, Mayan children 1) agreed to inform an ignorant person to the same extent when they had watched the hiding event and when they had only seen the initial pair of objects but not the hiding (see Figure 3); 2) explicitly reported in $55 \%$ of the trials of the ignorance condition that they knew which object had been hidden in the box; 3) against our dual-process prediction, did not display a better metacognitive sensitivity in the informing task than in the explicit task (reporting whether they know) in the tricky "partial knowledge" condition, where they had only perceived the objects to be hidden.

\section{Higher Mayan overconfidence}

Why are Yucatec Mayan children much more overconfident than the German and the Japanese children? Let us observe that overconfidence is not specific to Mayan children, and is also exemplified in our other two groups of children in the partial knowledge condition of the explicit task. Indeed, performance expectations are routinely overestimated by preschoolers in a number of tasks involving memory span, learning, imitation, motor activities, and hide-and-seek games (Schneider, 1998). It has been hypothesized that children's overestimation of their own skills might be adaptive for acquiring them (Bjorklund, Gaultney \& Green, 1993; Finn \& Metcalfe, 2014). On the basis of these findings, what needs to be explained is why Mayan children are more willing to inform (especially in the Partial knowledge condition) and more willing to report that they know (especially in the Ignorance condition) than the German and the Japanese children in cases in which they objectively do not have the relevant information.

A tentative hypothesis would be to claim a role for the autonomy-independence dimension of child-rearing practices. As seen above (see Fig. 1), Yucatec Mayan cultures value autonomy in children's agency comparatively more than either German or Japanese

\footnotetext{
${ }^{38}$ Note that in Figure 2 the accurate responses were coded slightly differently than here. For example, in the informing task, if children decided to inform, their verbal responses to another person were considered along with their informing decisions. In Figure 3, coding was restricted to children's informing decisions.
} 
cultures (Gaskins \& Paradise, 2010). With this in mind, an explanation of our findings might be that parental feedback to children's utterances is more readily available throughout childhood in both the German and Japanese cultures than in the Yucatec Mayan context. This in turn might allow German and Japanese children to be more or less tuned to their own knowledge states. Yucatec Mayan children's limited experience with formal learning and direct adult instruction and their autonomy for selecting their own learning goals in their everyday lives might lead them to be overly confident in providing information to others as well as in reporting that they know a given fact. More cross-cultural developmental research would be needed to test this hypothesis.

There are two reasons to believe, however, that this first hypothesis may not be the whole story. As claimed in section 2, all young children, at least in the cultures that have been tested, learn from observation, detect new information, get help when needed, and ask and respond to questions (Gauvain et al., 2013; Goupil et al., 2016). They need to deploy metacognitive sensitivity to what they do or do not know yet -in that procedural sense of knowing-, even if it is not expressed in their verbal behaviour (Cunnigham \& Weaver, 1989).

A second reason for rejecting the metacognitive deficit account is that, as far as Western children are concerned, children's unrealistic predictions have turned out to be unrelated to metacognitive deficiencies. Research about Western pre-schoolers' sensitivity to learning suggests that their overconfidence is not due to a lack of metacognitive awareness, but to a failure in expressing it in a given type of task (Lipowski, Merriman, \& Dunlovsky, 2013). Hence, the idea that Mayan children have a comparatively diminished sensitivity to error might equally not be the most plausible explanation of their comparatively higher overconfidence.

An alternative hypothesis would be that Mayan children, in our particular tasks, might give more weight to a perceptual familiarity heuristic as a cue for knowledge than the other two groups. ${ }^{39}$ It is a general tendency in children to give more weight to familiarity with the global situation than to the elements strictly relevant to the question. One might hypothesize, however, that the influence of a familiarity cue is higher in children who mainly perform wide-scale observational learning (that is: have a holistic form of attention) than in children who have mainly developed object-based attention through formal learning (Shneidman et al.,

\footnotetext{
${ }^{39}$ A sense of familiarity with the two objects they saw (in the partial knowledge condition of their explicit task) has been hypothesized in Rohwer et al. (2012) to explain why children unduly report that they know which object is hidden. In the same spirit, Kim et al. (2016) proposed that children's evaluation of knowledge relies on a gradient of information. While partial perceptual knowledge (of object type) is insufficient for full perceptual knowledge (object identity), the children can interpret familiarity, as likely knowledge irrespective of its content (as also do adults in memory tasks).
} 
2016). Again, more cross-cultural developmental research would be needed to test this hypothesis.

A third hypothesis, however, might offer a promising account, possibly in combination with the preceding one. In Western developmental studies, children's overconfidence has been robustly shown to derive from a motivational bias. Young children seem to take their high motivation for performing a given task as predicting success in it. Interestingly, this wishful thinking bias has been shown to be enhanced in verbal tests, and also in unfamiliar test contexts (Schneider \& Lockl, 2002). Both conditions are present in our test. Mayan children might find it definitely quite puzzling to be asked to inform an adult character whose perceptual access is deliberately blocked, and to be selected as informants when the adult experimenter could very well inform himself. They might be highly motivated, however, to inform and to report what they know.

\section{Mayan dual-process metacognition: a critical discussion}

As a reminder, a dual view of metacognition claims that although an opt-out task involves procedural metacognition - i.e. feelings of uncertainty-, an explicit task involves analytic metacognition - i.e. concepts and beliefs about one's own mind. A dual view of metacognition predicts that all the children should tend to form distinct evaluations in an opt-out task and in an explicit task. Namely, they should be more sensitive to what the perceptual information they have in the informing task than in the explicit task. In the partial knowledge condition, Japanese and German children were indeed more accurate when choosing to inform than when reporting whether they knew. Mayan children's performances, however, failed to present this contrast. How can we explain the absence of facilitation of what seemed to be a procedural task - informing someone - in the case of Mayan children?

To explain this, our third hypothesis for explaining Mayan children's overconfidence needs to be further developed: the absence of performance differentiation between our two tasks may be explained by how our "informing" task has been respectively perceived and processed by Japanese and German children, on the one hand, and Mayan children, on the other hand. The first two groups of children belong to the middle-class of industrial societies; they have been treated as conversational and informational partners from infancy; they have routinely been encouraged to volunteer information to help adults. In traditional rural societies, such as the Mayas, in contrast, children become conversational partners at a later point in development than in industrial societies. Caregivers and family adults do not expect 
to the same extent informational cooperation from children. Our 'informing scenario' might, then, have a different meaning in a Mayan context, and require different cognitive resources for children playing a part in it. Let us briefly point out how children might understand the scenario as a function of their culture.

From the Western and Japanese children's viewpoint, our informing experiment, like most of the tests in developmental psychology, looks like abstract pretend-play. The child is invited to 'help' someone sitting in the experience room, and to imagine that this person needs to be accurately informed. It is left to children's imagination, however, why the character actually needs the information. Western children easily make sense of this situation, and indeed find it easier to recognize the real amount of information they have in the partial knowledge condition than to report about what they know.

From the viewpoint of Mayan children, the informing scenario is not such a straightforward matter, particularly in the partial knowledge condition. Mayan children are often asked to inform adults about things that children know. They are not asked, however, "known-answer" questions, as instantiated in our informing scenario. ${ }^{40}$ Second, as discussed in section 2, informing a stranger is an unusual situation that requires some thinking. Children may communicate with strangers, but may remain vague and even be inaccurate in what they say. Third, Mayan children use everyday activities as the theme of their interpretive, i.e. imitation-based pretend-play; they do not perform inventive, i.e. "as-if" pretend-play (Gaskins, 2013). They have had little if any exposure to fictions (Danziger, 2010). They may have found, then, our test scenario puzzlingly artificial and implausible.

Now, assuming that the business of responding to known-answer questions is not as intuitive (i.e., metacognitively fluent) for Mayan children as it is for German and Japanese children, we need to understand why a difference in task fluency would influence their response pattern in the Partial Knowledge condition, and not in the Full Knowledge and the Ignorance conditions as well. We might observe, in response, that the Partial Knowledge condition in the informing task combines two features in the case of Mayan children; first, as just discussed, the informing behaviour is an unusual one, making it no less demanding and controlled than the explicit task. Second, this condition is more demanding. In the full Knowledge condition, children feel subjectively certain that they have watched the hiding object. In the Ignorance condition, children feel subjectively certain that they did not see anything. In the Partial Knowledge condition, in contrast, children saw two toys, one of which

\footnotetext{
${ }^{40}$ Gaskins (personal communication).
} 
was subsequently hidden in the box. The relevant stimulus, then, has been seen. This creates an illusion of fluency, which in turn makes a prediction of knowledge look more attractive than in the other two conditions. The two difficulties (higher task disfluency and higher subjective uncertainty), may explain why Mayan children fail to present the dissociative pattern that was found in German and Japanese children.

If this line of reasoning is correct, the performance contrast found in our German and Japanese participants' performances might express the difference between the experiencebased metacognition elicited in the implicit test, and the analytic form of metacognition, elicited in the explicit test. In our Mayan participants' performance, however, no similar contrast might have been elicited, because, in their case, the informing behaviour is a controlled practice, imbued with contrasted social meanings and beliefs, rather than a routine experience-based practice. Again, additional studies involving Mayan children as well as children from other traditional societies would be needed to test this hypothesis.

\section{Conclusion: Are there culture-specific relations between mindreading and}

\section{metacognition?}

Diversity in mindreading becomes manifest through differences in its developmental pattern: not only timing, but also the order in which constituent processes are acquired differ across culture. We discussed the anthropological evidence that might account for these differences. In the West, very young children are educated to express what they want and intend to do. Western societies assume that ostensible transparency -telling others what you want, intend, believe, etc. -benefits cooperation and stability in social interactions. ${ }^{41}$ Traditional MesoAmerican and Pacific small-size communities, in contrast, consider institutionalized opacity to provide a more stable foundation of balanced politics, enabling both cooperation and the pursuit of private goals. The transparency-opacity value was found to directly impact communication with children, and generate distinctive transparent vs. opaque roles of mindreading. There are cultures with no dyadic, face-to-face adult communication with infants, in which children's utterances are not rephrased or expanded by caregivers, nor understood as an expression of children's inner desires or intentions. In some cultures, children are explicitly invited to say what the addressee expects them to say, a practice divorcing communicated contents from speakers' individual (non-relational) mental states. It

\footnotetext{
${ }^{41}$ As is well known, however, this transparency invites deceptive ways of being open, which in turn requires strategies of epistemic vigilance from addressees.
} 
should now be clear that, as was pointed out long ago (Lillard, 1998), false belief tasks have been tailored to test children from a Western culture.

What do we know about the existence and possible sources of diversity in metacognition? Very little, indeed. Given the scarce evidence available, we conjectured that the well-documented differences in the cognitive content of attention, in the type of learning formal or observational -, and in the pragmatic standards of ordinary communication should be major sources of metacognitive diversity.

An additional question that remains to be addressed is to know whether or not these practices can influence metacognition independently of any top-down effect from mindreading. An important milestone in addressing this question is the study by Shneidman, et al. (2016) discussed in section 2. This study shows that whereas US 18-month-old children only imitate a given behaviour when first directly addressed by an adult, Mayan children of the same age do not need to be addressed to imitate a behaviour. What these data suggest is that children deploy differently their attention across culture. Whereas Western caregivers scaffold children's attention, through specific communicational routines (such as "addressing" and other ostensive signals), Mayan caregivers leave the children autonomous in the control and monitoring of information (see also Rogoff et al. 1993). Such an explanation goes against the view that an innate sensitivity to ostensive signals, a sensitivity that would directly depend on a human metarepresentational ability, should be needed to trigger specific expectations of relevance in infants (Csibra \& Gergely, 2009). Shneidman's et al. (2016) study elegantly demonstrates that relevance can be monitored independently of any form of mindreading or conceptual expectation (see also Proust, 2013, 2016).

When we compare the factors that might influence both mindreading and metacognition, we see that a common feature is autonomy. Granting that autonomy can privilege either opaque or transparent mindreading, one should also find opaque and transparent forms of "analytic" metacognition. Although diversity in communication has been shown to directly impact both mindreading and metacognitive diversity in young children, different factors seemed to be respectively involved. The structure of interaction directly impacts mindreading through a communicative structure enhancing informational autonomy or dependence. The pragmatic standards of communication directly impact experience-based metacognition through pragmatic rules emphasizing the crucial informational cues that need to be monitored.

Much work remains to be done in order to understand the full range of top-down effects of diversity in mindreading on experience-based metacognition, as well as the 
reciprocal influence of metacognitive practices on mindreading ability. Far from being a side issue, the study of their interaction seems to be a precondition for coming up with a better account of both types of skills. The collaboration of anthropologists and developmental psychologists is a key to the success of this project.

\section{References}

Ahn, S., \& Miller, S. A. (2012). Theory of mind and self-concept: A comparison of Korean and American children. Journal of Cross-Cultural Psychology, 43(5), 671-686.

Avis, J., \& Harris, P. L. (1991). Belief-Desire Reasoning among Baka Children: Evidence for a Universal Conception of Mind. Child development, 62(3), 460-467.

Balcomb, F. K., \& Gerken, L. (2008). Three-year-old children can access their own memory to guide responses on a visual matching task. Developmental science, 11(5), 750-760.

Barrett, H. C., Broesch, T., Scott, R. M., He, Z., Baillargeon, R., Wu, D. \& Laurence, S. (2013). Early false-belief understanding in traditional non-Western societies. Proceedings of the Royal Society of London B: Biological Sciences, 280(1755), 20122654.

Bernard, S., Proust, J., \& Clément, F. (2015). Procedural Metacognition and False Belief Understanding in 3-to 5-Year-Old Children. PloS one, 10(10), e0141321.

Bjorklund, D. F., Gaultney, J. F., \& Green, B. L. (1993). I watch therefore I can do": The development of metaimitation over the preschool years and the advantage of optimism in one's imitative skills. Emerging themes in cognitive development, 2, 79-102.

Bourdieu, P. (1977). Outline of a Theory of Practice. Cambridge Studies in Social and Cultural Anthropology (Vol. 16). Cambridge: Cambridge University Press.

Brennan, T., Vikan, R., \& Dybdahl, R. (2007). Are tip-of-the-tongue states universal? Evidence from an unwritten language. Memory, 15, 167-176.

Butterfill, S. A. (2013). Interacting mindreaders. Philosophical Studies, 165(3), 841-863.

Callaghan, T., Rochat, P., Lillard, A., Claux, M. L., Odden, H., Itakura, S., Singh, S. (2005). Synchrony in the Onset of Mental-State Reasoning: Evidence From Five Cultures. Psychological Science, 16(5), 378-384. doi: 10.1111/j.0956-7976.2005.01544.

Carpendale, J. I., \& Chandler, M. J. (1996). On the distinction between false belief understanding and subscribing to an interpretive theory of mind. Child Development, 67(4), 1686-1706. 
Carpendale, J. I., \& Lewis, C. (2004). Constructing an understanding of mind: The development of children's social understanding within social interaction.Behavioral and brain sciences, 27(01), 79-96.

Chouinard, M. M., Harris, P. L., \& Maratsos, M. P. (2007). Children's questions: A mechanism for cognitive development. Monographs of the Society for Research in Child Development, 1-129.

Couchman, J. J., Beran, M. J., Coutinho, M. V., Boomer, J., \& Smith, J. D. (2012). Evidence for animal metaminds. In M. Beran, J. Brandl, J. Perner, J. Proust (eds.) Foundations of metacognition, 21-35. Oxford: Oxford University Press.

Csibra, G., \& Gergely, G. (2009). Natural pedagogy. Trends in cognitive sciences, 13(4), 148153.

Csibra, G., \& Gergely, G. (2011). Natural pedagogy as evolutionary adaptation. Philosophical Transactions of the Royal Society B: Biological Sciences,366(1567), 1149-1157.

Cunningham, J. G., \& Weaver, S. L. (1989). Young children's knowledge of their memory span: Effects of task and experience. Journal of Experimental Child Psychology, 48(1), $32-44$.

Danziger, E. (2006). The thought that counts: interactional consequences of variation in cultural theories of meaning. In N.J. Enfield and S.C. Levinson (eds.), Roots of human sociality: Culture, cognition and interaction, New York: Berg. 11(4), 259-278.

Danziger, E. (2010). On trying and lying: Cultural configurations of Grice's Maxim of Quality. Intercultural Pragmatics, 7(2), 199-219.

De Villiers, J. G., \& De Villiers, P. A. (2000). Linguistic determinism and the understanding of false. In P. Mitchell and K. Riggs, (eds.), Children's reasoning and the mind, 191228, Hove: East Sussex: Psychology Press.

Duranti, A. (1988). Intentions, language, and social action in a Samoan context. Journal of Pragmatics, 12(1), 13-33.

Duranti, A. (1993). Truth and intentionality: an ethnographic critique. Cultural Anthropology, 8(2), 214-245.

Feinberg, R. (1998) Oral Traditions of Anuta: A Polynesian Outlier in the Solomon Islands. Oxford: Oxford University Press.

Feinman, S. (1982). Social referencing in infancy. Merrill-Palmer Quarterly (1982-), 445470.

Finn, B., \& Metcalfe, J. (2014). Overconfidence in children's multi-trial judgments of learning. Learning and Instruction, 32, 1-9. 
Flavell, J. H. (2000). Development of children's knowledge about the mental world. International journal of Behavioral Development, 24(1), 15-23.

Gallagher, S. (2012). In defense of phenomenological approaches to social cognition: interacting with the critics. Review of Philosophy and Psychology, 3(2), 187-212.

Gallagher, S., \& Hutto, D. (2008). Understanding others through primary interaction and narrative practice. In: J. Zlatev, T.P. Racine, C. Sinha, \& E. Itkonen, (Eds.). The shared mind: Perspectives on intersubjectivity (Vol. 12) pp. 17-38. John Benjamins Publishing.

Gallese, V., \& Goldman, A. (1998). Mirror neurons and the simulation theory of mindreading. Trends in cognitive sciences, 2(12), 493-501.

Gaskins, S. (1990). Mayan exploratory play and development (Doctoral dissertation, Univ. of Chicago, Dept. of Education).

Gaskins, S. (1999). Children's daily lives in a Mayan village: A case study of culturally constructed roles and activities. In Göncü, A. (ed.), Children's engagement in the world: Sociocultural perspectives, 25-60. Cambridge: Cambridge University Press.

Gaskins, S., \& Paradise, R. (2010). Learning Through Observation in Daily Life. In D.F. Lancy, J.C. Bock, \& S. Gaskins, S. (eds.) The anthropology of learning in childhood. Rowman \& Littlefield, 85-116.

Gaskins, S. (2013). Pretend play as culturally constructed activity. In M. Taylor (ed.), The Oxford Handbook of the Development of Imagination, 224-247. Oxford: Oxford University Press.

Gauvain, M. (1998). Culture, development, and theory of mind: Comment on Lillard (1998). Psychological Bulletin, Vol 123(1), Jan 1998, 37-42. http://dx.doi.org/10.1037/00332909.123.1.37.

Gauvain, M., Munroe, R. L., \& Beebe, H. (2013). Children's questions in cross-cultural perspective: A four-culture study. Journal of Cross-Cultural Psychology,44(7), 11481165.

Gerken, L., Balcomb, F. K., \& Minton, J. L. (2011). Infants avoid 'labouring in vain'by attending more to learnable than unlearnable linguistic patterns. Developmental Science, 14(5), 972-979.

Goupil, L., Romand-Monnier, M., \& Kouider, S. (2016). Infants ask for help when they know they don't know. Proceedings of the National Academy of Sciences, 113(13), 34923496.

Greenfield, P. M., Maynard, A. E., \& Childs, C. P. (2003). Historical change, cultural learning, and cognitive representation in Zinacantec Maya children. Cognitive Development, 18(4), 455-487.

Grice, H. P. (1989). Logic and conversation. In: Studies in the Way of Words. Cambridge: 
Harvard University Press. 22-40.

Groark, K. P. (2013). Toward a cultural phenomenology of intersubjectivity: The extended relational field of the Tzotzil Maya of highland Chiapas, Mexico. Language \& Communication, 33(3), 278-291.

Harris, P. L. (1992). From simulation to folk psychology: The case for development. Mind \& Language, 7(1-2), 120-144.

Harris, P. L., Brown, E., Marriott, C., Whittall, S., \& Harmer, S. (1991). Monsters, ghosts and witches: Testing the limits of the fantasy-reality distinction in young children. British Journal of Developmental Psychology, 9(1),105-123.

Henrich, J. Heine, S.J. \& Norenzayan, A. (2010). The weirdest people in the world? Behavioral and Brain Sciences, 33, 2-3, 61-83. Doi.org/10.1017/S0140525X0999152X.

Hofer, J., \& Chasiotis, A. (2003). Congruence of life goals and implicit motives as predictors of life satisfaction: Cross-cultural implications of a study of Zambian male adolescents. Motivation and Emotion, 27(3), 251-272.

Huguet, P., \& Régner, I. (2007). Stereotype threat among schoolgirls in quasi-ordinary classroom circumstances. Journal of Educational Psychology, 99(3), 545-560.

Kâğıtçıbaşı, C. (2005). Autonomy and relatedness in cultural context: Implications for self and family. Journal of Cross-cultural Psychology, 36(4), 403-422.

Keane, W. (2008). Others, other minds, and others' theories of other minds: An afterword on the psychology and politics of opacity claims. Anthropological Quarterly, 81(2), 473482.

Keller, H. (2012). Autonomy and relatedness revisited: Cultural manifestations of universal human needs. Child Development Perspectives, 6(1), 12-18.

Keller, H., Yovsi, R., Borke, J., Kärtner, J., Jensen, H., \& Papaligoura, Z. (2004).

Developmental Consequences of Early Parenting Experiences: Self-Recognition and Self-Regulation in Three Cultural Communities. Child development, 75(6), 1745-1760.

Kepecs, A., \& Mainen, Z. F. (2012). A computational framework for the study of confidence in humans and animals. Philosophical Transactions of the Royal Society of London B: Biological Sciences, 367(1594), 1322-1337.

Kim, S., Paulus, M., Sodian, B., \& Proust, J. (2016). Young children's sensitivity to their Oown ignorance in nforming others. PloS one, 11(3), e0152595.

Kim, S., Paulus, M., Sodian, B., Itakura, S., Ueno, M., Senju, A., \& Proust, J. (under review). Cross-cultural studies of mindreading and metacognition.

Kim, S., Le Guen, O., Paulus, M., Sodian, B., \& Proust, J. (in preparation). Are children sensitive to what they know? : An insight from Yucatec Mayan children. 
Koriat, A., \& Ackerman, R. (2010). Choice latency as a cue for children's subjective confidence in the correctness of their answers. Developmental Science, 13(3), 441-453.

Koriat, A., Ackerman, R., Lockl, K., \& Schneider, W. (2009). The memorizing effort heuristic in judgments of learning: A developmental perspective. Journal of Experimental Child Psychology, 102(3), 265-279.

Koriat, A., \& Levy-Sadot, R. (1999). Processes underlying metacognitive judgments: Information-based and experience-based monitoring of one's own knowledge. In S. Chaiken, YTrope, (Eds). (1999). Dual-process Theories in Social Psychology, (pp. 483-502). New York, NY, US: Guilford Press.

Kornell, N., Son, L. K., \& Terrace, H. S. (2007). Transfer of metacognitive skills and hint seeking in monkeys. Psychological Science, 18(1), 64-71.

Kovács, Á. M., Téglás, E., \& Endress, A. D. (2010). The social sense: Susceptibility to others' beliefs in human infants and adults. Science, 330(6012), 1830-1834.

Kuhn, D. (2000). Metacognitive development. Current directions in psychological science, 9(5), 178-181.

Kuntoro, I. A., Saraswati, L., Peterson, C., \& Slaughter, V. (2013). Micro-cultural influences on theory of mind development: A comparative study of middle-class and pemulung children in Jakarta, Indonesia. International Journal of Behavioral Development, 37(3), 266-273.

Lecce, S., Demicheli, P., Zocchi, S., \& Palladino, P. (2015). The origins of children's metamemory: The role of theory of mind. Journal of experimental child psychology, 131, 56-72.

Leslie, A. M., Friedman, O., \& German, T. P. (2004). Core mechanisms in 'theory of mind'. Trends in cognitive sciences, 8(12), 528-533.

Lillard, A. (1998). Ethnopsychologies: cultural variations in theories of mind. Psychological bulletin, 123(1), 3-32.

Liszkowski, U., Brown, P., Callaghan, T., Takada, A., \& de Vos, C. (2012). A prelinguistic gestural universal of human communication. Cognitive Science, 36(4), 698-713.)

Liu, Y., Wang, Y., Luo, R., \& Su, Y. (2014). From the external to the internal Behavior clarifications facilitate theory of mind (ToM) development in Chinese children. International Journal of Behavioral Development, 40, 1, 21-30.

Liu, D., Wellman, H. M., Tardif, T., \& Sabbagh, M. A. (2008). Theory of mind development in Chinese children: a meta-analysis of false-belief understanding across cultures and languages.

Lockl, K., \& Schneider, W. (2007). Knowledge about the mind: Links between theory of mind and later metamemory. Child Development, 78(1), 148-167. 
Markus, H. R., \& Kitayama, S. (1991). Culture and the self: Implications for cognition, emotion, and motivation. Psychological Review, 98(2), 224-253.

Matsui, T., Rakoczy, H., Miura, Y., \& Tomasello, M. (2009). Understanding of speaker certainty and false-belief reasoning: a comparison of Japanese and German preschoolers. Developmental Science, 12(4), 602-613.

Mayer, A., \& Träuble, B. E. (2013). Synchrony in the onset of mental state understanding across cultures? A study among children in Samoa. International Journal of Behavioral Development, 37(1), 21-28.

Mayer, A., \& Träuble, B. (2015). The weird world of cross-cultural false-belief research: A true-and false-belief study among Samoan children based on commands. Journal of Cognition and Development, 16(4), 650-665.

McGeer, V., \& Pettit, P. (2002). The self-regulating mind. Language \& Communication, 22(3), 281-299.

Merlan, F., \& Rumsey, A. (1991). Ku Waru: language and segmentary politics in the western Nebilyer valley, Papua New Guinea (Vol. 10). Cambridge: Cambridge University Press.

Moriguchi, Y., Okumura, Y., Kanakogi, Y., \& Itakura, S. (2010). Japanese children's difficulty with false belief understanding: is it real or apparent?. Psychologia, 53(1), 3643.

Naito, M., \& Koyama, K. (2006). The development of false-belief understanding in Japanese children: Delay and difference?. International Journal of Behavioral Development, 30(4), 290-304.

Nisbett, R. E., \& Masuda, T. (2003). Culture and point of view. Proceedings of the National Academy of Sciences, 100(19), 11163-11170.

Nisbett, R. E., \& Miyamoto, Y. (2005). The influence of culture: holistic versus analytic perception. Trends in cognitive sciences, $9(10), 467-473$.

Nisbett, R. E., Peng, K., Choi, I., \& Norenzayan, A. (2001). Culture and systems of thought: holistic versus analytic cognition. Psychological Review, 108(2), 291.

Nisbett, R.E. (2003). The Geography of Thought. How Asians and Westerners thing differently.. and why. New York: Free Press.

Ochs, E. (1982). Talking to children in Western Samoa. Language in Society,11(01), 77-104.

Ochs-Keenan, E. O. (1976). The universality of conversational postulates. Language in society, 5(01), 67-80.

Ochs, E., \& Schieffelin, B. (1982/2001). Language acquisition and socialization: Three developmental stories and their implications. First published as Socio-linguistic working paper (1982), 105, by the National Institute of Education, Washington D.C. 
pp. 3-91; republished in A. Duranti (ed.), (2001) Linguistic Anthropology: A Reader, pp. 263-301. Malden, MA: John Wiley \& Sons.

Papafragou, A. (2012). Mindreading and verbal communication. Mind \& Language, 17(1-2), 55-67.)

Paulus, M., Proust, J., \& Sodian, B. (2013). Examining implicit metacognition in 3.5-year-old children: An eye-tracking and pupillometric study. Frontiers in psychology, 4, 145-162.

Perner, J. (1991). Understanding the representational mind. Cambridge, Mass: The MIT Press.

Perner, J. (2012). MiniMeta: in search of minimal criteria for metacognition. In M. Beran, J. Brandl, J. Perner \& J. Proust (eds.) Foundations of metacognition, 94-116, Oxford: Oxford University Press.

Piaget, J. (1948/1973). To understand is to invent: The future of education. New York: Penguin Books.

Pratt, C., \& Bryant, P. (1990). Young children understand that looking leads to knowing (so long as they are looking into a single barrel). Child Development,61(4), 973-982.

Proust, J. (2012). Metacognition and mindreading: one or two functions? in: M. Beran, J. Brandl, J. Perner \& J. Proust (Eds.), The Foundations of Metacognition. Oxford: Oxford University Press. (2012), 234-251.

Proust, J. (2013), The Philosophy of Metacognition. Mental Agency and Self-awareness. Oxford: Oxford University Press.

Proust, J. (2016). The evolution of communication and metacommunication in primates. Mind and Language, 31, 2, 177-203.

Robbins, J. (2008). On not knowing other minds: Confession, intention, and linguistic exchange in a Papua New Guinea community. Anthropological Quarterly, 81(2), 421429.

Robbins, J., \& Rumsey, A. (2008). Introduction: Cultural and linguistic anthropology and the opacity of other minds. Anthropological Quarterly, 81(2), 407-420.

Rogoff, B., Mistry, J., Göncü, A., Mosier, C., Chavajay, P., \& Heath, S. B. (1993). Guided participation in cultural activity by toddlers and caregivers. Monographs of the Society for Research in Child development, 1-179.

Rogoff, B., Mejía-Arauz, R., \& Correa-Chávez, M. (2015). Chapter One-A Cultural Paradigm - Learning by Observing and Pitching In. Advances in child development and behavior, 49, 1-22.

Rosaldo, M. Z. (1982). The things we do with words: Ilongot speech acts and speech act theory in philosophy. Language in Society, 11(02), 203-237. 
Rohwer, M., Kloo, D., \& Perner, J. (2012). Escape from metaignorance: How children develop an understanding of their own lack of knowledge. Child Development, 83(6), 1869-1883.

Rumsey, A. (2008). Confession, anger and cross-cultural articulation in Papua New Guinea. Anthropological Quarterly, 81(2), 455-472.

Sahlins, M. (1983). Other times, other customs: the anthropology of history. American Anthropologist, 85(3), 517-544

Schieffelin, B. B. (2008). Speaking only your own mind: reflections on talk, gossip and intentionality in Bosavi (PNG). Anthropological Quarterly, 81(2), 431-441.

Schneider, W. (1998). Performance prediction in young children: Effects of skill, metacognition and wishful thinking. Developmental Science, 1(2), 291-297.

Schneider, W. (2008). The development of metacognitive knowledge in children and adolescents: Major trends and implications for education. Mind, Brain, and Education, 2(3), 114-121.

Schneider, W., \& Lockl, K. (2002). 10 The development of metacognitive knowledge in children and adolescents. In T. J. Perfect \& B. Schwartz, Applied metacognition, pp. 224- 257. Cambridge $=$ Cambridge University Press.

Schooler, C. (2007). Culture and Social Structure.in S. Kitayama \& D. Cohen (eds.). Handbook of Cultural Psychology, pp. 370-388. New York: The Guildford Press.

Schwartz, B. L. (1999). Sparkling at the end of the tongue: The etiology of tip-of-the-tongue phenomenology. Psychonomic Bulletin \& Review, 6(3), 379-393.

Shahaeian, A., Henry, J. D., Razmjoee, M., Teymoori, A., \& Wang, C. (2015). Towards a better understanding of the relationship between executive control and theory of mind: an intra-cultural comparison of three diverse samples. Developmental science, 18(5), 671-685.

Shahaeian, A., Nielsen, M., Peterson, C., \& Slaughter, V. (2014b). Cultural and family influences on children's theory of mind development: A comparison of Australian and Iranian school-age children. Journal of Cross-Cultural Psychology, 45, 555-568.

Shahaeian, A., Nielsen, M., Peterson, C., Slaughter, V., \& Aboutalebi, M. (2014a). Knowledge and belief understanding among Iranian and Australian preschool children. Journal of Cross-Cultural Psychology, 45, 1643-1654.

Shahaeian, A., Peterson, C. C., Slaughter, V., \& Wellman, H. M. (2011). Culture and the sequence of steps in theory of mind development. Developmental psychology, 47(5), 1239.

Shneidman, L., Gaskins, S., \& Woodward, A. (2016). Child-directed teaching and social learning at 18 months of age: evidence from Yucatec Mayan and US infants. Developmental Science, 19, 372-381. doi: 10.1111/desc.12318 
Shore, B. (1996). Culture in Mind. Oxford: Oxford University Press.

Slaughter, V., \& Perez-Zapata, D. (2014). Cultural variations in the development of mind reading. Child Development Perspectives, 8(4), 237-241.

Spencer, S. J., Steele, C. M., \& Quinn, D. M. (1999). Stereotype threat and women's math performance. Journal of Experimental Social Psychology, 35(1), 4-28.

Stasch, R. (2008). Knowing minds is a matter of authority: Political dimensions of opacity statements in Korowai moral psychology. Anthropological Quarterly,81(2), 443-453.

Talhelm, T., Zhang, X., Oishi, S., Shimin, C., Duan, D., Lan, X., \& Kitayama, S. (2014). Large-scale psychological differences within China explained by rice versus wheat agriculture. Science, 344(6184), 603-608

Throop, C. J. (2010). In the midst of action. In K.M. Murphy \& C.J. Throop (eds.) Toward an Anthropology of the Will, 28-49. Stanford: Stanford University Press.

Throop, C. J. (2011). Suffering, empathy and Ethical Modalities of Being in Yap, In D. W. Hollan \& C. J. Throop, (eds), The Anthropology of Empathy: Experiencing the Lives of Others in Pacific Societies. New York: Berghahn Books, 119-149.

Vinden, P. G. (1996). Junin Quechua children's understanding of mind. Child Development, 67(4), 1707-1716.

Wassmann, J., Träuble, B., \& Funke, J. (2013). Theory of mind in the Pacific. Reasoning across cultures Heidelberg Studies in Pacific Anthropology (Vol. 1). Heidelberg: Winter.

Watson, J. K., Gelman, S. A., \& Wellman, H. M. (1998). Young children's understanding of the non-physical nature of thoughts and the physical nature of the brain. British Journal of Developmental Psychology, 16(3), 321-335.

Wellman, H. M., Cross, D., \& Watson, J. (2001). Meta-analysis of theory-of-mind development: the truth about false belief. Child development, 72(3), 655-684.

Wellman, H. M., \& Liu, D. (2004). Scaling of theory-of-mind tasks. Child development, 75(2), 523-541.

Zawidzki, T. W. (2013). Mindshaping: A new framework for understanding human social cognition. Cambridge, Mass: MIT Press. 


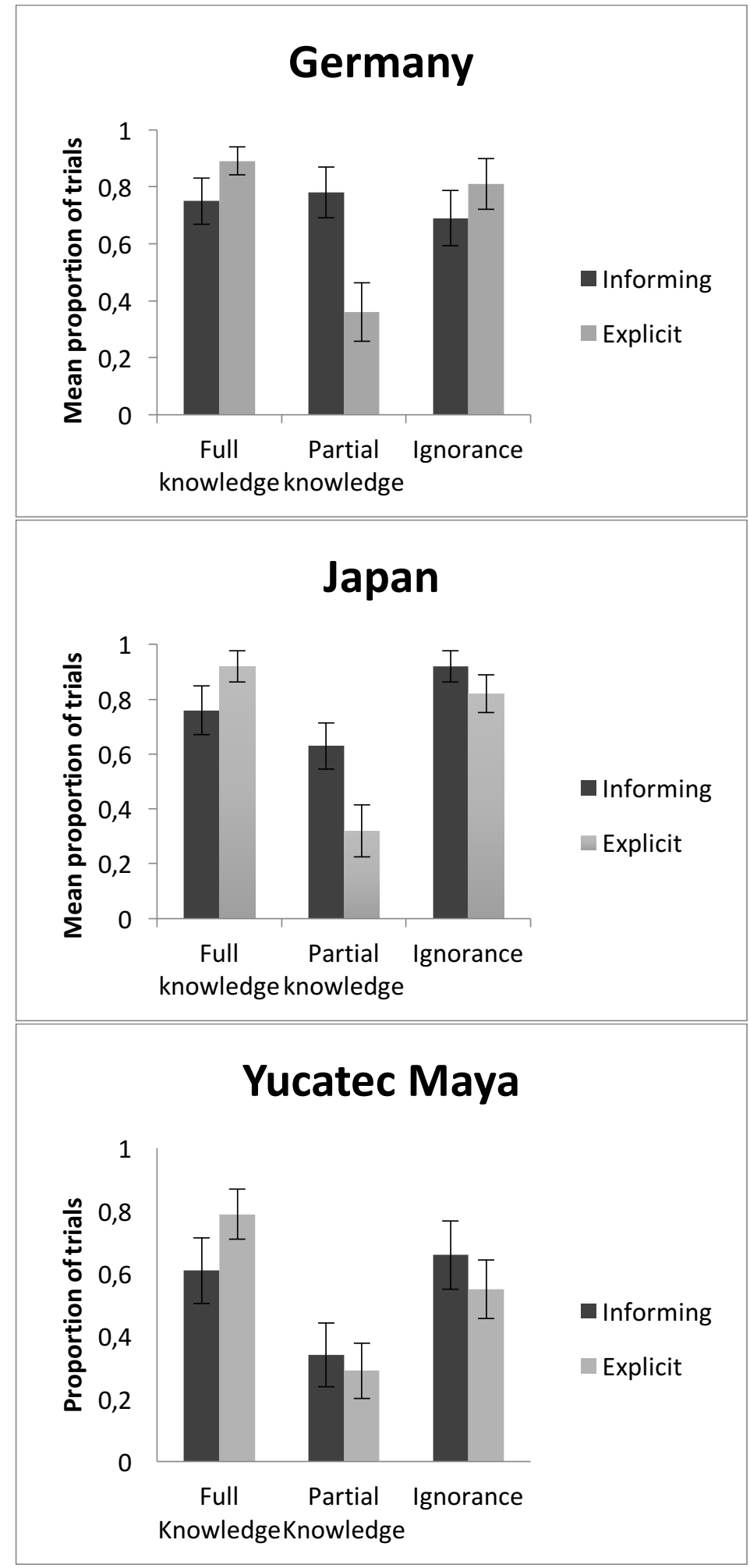

Figure 2. Four-year-old children's accurate responses in the two tasks in our three cultural groups. Error bars indicate Standard Errors. German data reproduced from Kim et al. (2016); Japanese data reproduced from Kim et al. (under review), Yucatec Mayan data reproduced from Kim et al. (in prep). 


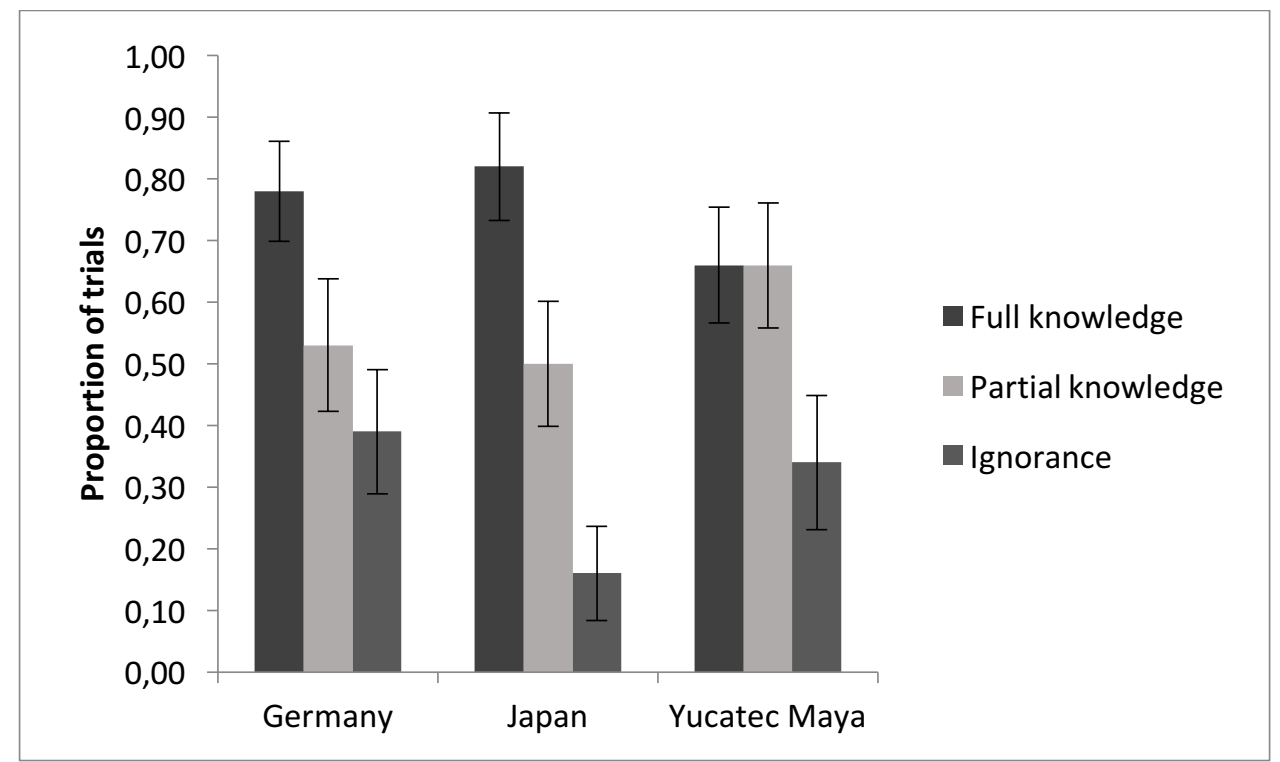

Figure 3. Mean proportion of trials in which 4-year-old children agreed to inform (as opposed to refusal to inform) as a function of Condition and Country. Error bars indicate standard errors. (.German data reproduced from Kim et al. (2016); Japanese data reproduced from Kim et al. (under review); Yucatec Mayan data from Kim et al. (in prep). 